This is a repository copy of Hierarchical set-point optimization and feedforward strategy for collector defocusing of a solar plant in the Depósito de Investigación de la Universidad de Sevilla

Version: Author Accepted Version

Citation: A.J. Sánchez, A.J. Gallego, J.M. Escaño, E.F. Camacho, Hierarchical set-point optimization and feedforward strategy for collector defocusing of a solar plant, Solar Energy, Volume 220, 15 May 2021, Pages 282-294. 10.1016/j.solener.2021.01.019

To cite this publication, please use the final published version (if applicable). Please check the document version above.

Copyright: Other than for strictly personal use, it is not permitted to download, forward or distribute the text or part of it, without the consent of the author(s) and/or copyright holder(s), unless the work is under an open content license such as Creative Commons.

Takedown policy: Please contact us (idus@us.es) and provide details if you believe this document breaches copyrights. We will remove access to the work immediately and investigate your claim 


\title{
Hierarchical Set-point Optimization and FeedForward Strategy for Collector Defocusing of a Solar Plant
}

\author{
A. J. Sánchez ${ }^{\mathrm{a}, *}$, A. J. Gallego ${ }^{\text {a }}$, J. M. Escaño ${ }^{\mathrm{a}}$, E. F. Camacho ${ }^{\mathrm{a}}$ \\ ${ }^{a}$ Departamento de Ingeniería de Sistemas y Automática, Universidad de Sevilla, Camino de los Descubrimientos s/n, 41092 Sevilla, Spain
}

\begin{abstract}
One of the main control objectives in parabolic trough solar thermal plants is to maintain the outlet temperature around an operating point. For this, a synthetic oil flow is used as the main control variable. However, another crucial system of the plant is the defocusing safety system of the collectors to prevent the oil temperature from exceeding an upper limit to prevent its degradation. This will occur, in general, when the oil flow reaches the maximum possible and is not able to regulate anymore the temperature. This mechanism is generally applied based on heuristic rules and partial or total defocus, which leads to a large number of actuator actions and temperature oscillations. In commercial plants, this defocus mechanism is applied firstly to the last collector, and as necessary, other collectors are defocused. In addition, it must be taken into account that loops' parameters will be, in general, different.

In this work, a FeedForward-based strategy is proposed to control the outlet temperature of collectors 1,2 and 3 of a solar plant using the defocus angle as the manipulated variable. It is also proposed to dynamically obtain the setpoint temperatures for the first 3 collectors through an optimization based on the concentrated parameter model. The results of the simulations are presented in different situations where the good performance of the strategy is observed. It is shown how the dynamic modification of the set-points can avoid possible energy losses on occasions where a fixed set-point of temperature is not the optimal option.
\end{abstract}

Keywords: Solar Energy, Collector Defocus, FeedForward Control, Optimization, Model Predictive Control

\section{Introduction}

The energy generated by the sun is the largest source 3 of renewable energy available. In fact, other renewable energies such as wind come from the solar energy produced by the sun that reaches the earth. The use of solar energy is one of the alternatives to reduce the consumption of fossil fuels and in this way reduce the greenhouse gases generated by power generation plants based on fossil fuels. There is a global awareness due to climate change and the use of renewable energies such as solar energy which would help to reduce these greenhouse gases, mainly $\mathrm{CO}_{2}$ (Romero and González-Aguilar, 2014; Blanco and Miller, 2017), and which are causing the increase in global temperature.

Solar plants can be divided mainly into two main categories: (1) those of concentrated solar thermal technology (CSP), (2) those of solar photovoltaic (PV) technology. There is a third classification that is currently under research and development and is a hybrid technology that contains both a thermal and a photovoltaic part (PVT) (Zarrella et al., 2019). This work focuses on CSP plants

\footnotetext{
* Corresponding author

Email addresses: asanchezdelpozo@us.es (A. J. Sánchez), gallegolen@hotmail.com (A. J. Gallego), jescano@us.es (J. M. Escaño), efcamacho@us.es (E. F. Camacho)
}

with Parabolic Trough Collectors (PTC). It can be said that currently electrical production based on solar thermal technology is a reality and is in full operation with more than 100 commercial plants producing (Pitz-Paal, 2018) all over the world, where one of the most used CSP technologies is that of PTC. Among the PTC plants currently producing, we can find plants of large scale (50MW) such as: Palma del Rio in Spain, and very large scale plants (> $100 \mathrm{MW}$ ) such as KaXu Solar One $100 \mathrm{MW}$ in South Africa, NOOR I $160 \mathrm{MW}$ in Morocco, Mojave 2x140 MW and Solana $280 \mathrm{MW}$ in the US (both property of Atlantica Yield), and the three new plants currently under construction in Dubai, United Arab Emirates, launched by Dubai Electricity \& Water Authority (DEWA) a $600 \mathrm{MW}$ project (3 CSP plants, $200 \mathrm{MW}$ each) in which Abengoa is providing the solar parabolic trough field technology (Helioscsp.com News, 2018). More information about these CSP PTC plants can be found at NREL PTC (2020).

One of the greatest advantages of solar thermal concentrating plants is the use of molten salt tanks for thermal energy storage (TES) (Roca et al., 2016; Peiró et al., 2018), which can be used later to continue producing electric energy when there is no solar resource or when circumstances require it. Another possible method other than the use of molten salt tanks is the use of steam storage tanks (Prieto et al., 2018). However, it seems to be more 
convenient to use molten salt tanks in large scale solar plants where high storage capacities are needed (GonzálezRoubaud et al., 2017).

Typically commercial plants work by heating HTF to a nominal high solar field outlet temperature zone. The nominal outlet temperature is usually around $393^{\circ} \mathrm{C}$. Generally, the main objective, in relation to the solar field, is to maintain the output temperature of the solar field around this temperature set-point. Other objectives pursued in research are, among others, the reduction of plant costs, optimization of structures, improvements in energy storage strategies and optimization of production. In relation to the control and monitoring of the solar field outlet set-point temperature, numerous strategies have been proposed. A control for solar field temperature based on a Dynamic Matrix Control (DMC) is proposed in Lima et al. (2016) where a filter is included for the prediction of the error, improving the properties of disturbance rejection and robustness of the DMC. A distributed solar collector field temperature profile control using a PID plus a FeedForward $(\mathrm{FF})$ in series with an inlet oil temperature and radiation estimations using an Iterative Extended Kalman Filter is presented in Karamali and Khodabandeh (2017). In Fenchouche et al. (2017), authors presented a design of robust controller based on coefficient diagram method (CDM) to control the outlet temperature. The proposed scheme is a Feedforward plus a PID design by CDM to improve the speed of the system response. A Gain Scheduling Generalized Model Predictive Control for the New TCP100 Parabolic Trough Field of the Plataforma Solar de Almería is presented in Gallego et al. (2018). In Li et al. (2020) an efficient static FeedForward and a generalized disturbance-control equation strategy for concentrating solar energy harvesting is proposed to confront the weather and load fluctuations. Results show temperature deviation ranging between $-2{ }^{\circ} \mathrm{C}$ and $2.5{ }^{\circ} \mathrm{C}$.

In relation to the optimization of solar plants, important research is also being conducted. In Camacho and Gallego (2013) an optimization of a solar plant is presented by applying a hierarchical structure of 3 layers to calculate the optimal solar field temperature to increase the plant performance according to environmental conditions. In Sánchez et al. (2019b), a nonlinear optimization analysis and strategy is presented along with clustering to calculate the necessary control actions on the loops inlet valves to obtain a thermal balance of the solar field reducing the need for unnecessary defocus actions avoiding premature degradation of actuators and maintaining loops at similar temperatures, something important when working at high temperatures because production losses can occur due to loops with very different temperatures. In Merad et al. (2019), authors proposed a new parabolic cylinder collector design. They focused on the opening angle of reflective aperture area allowing a flexible parabolic trough shape, unlike the conventional design. The flexible structure is proposed in order to: control the absorbed temperature, obtain the maximum CSP temperature under different il- lumination and improve the production of the plant. In a different direction, Aguilar et al. (2019) discusses how the use of super-critical carbon dioxide ( $\mathrm{sCO} 2$ ) instead of synthetic Heat Transfer Fluids (HTF) can increase the energy conversion efficiency in PTC CSP plants.

However, it is not always possible to control the outlet temperature of the solar field only with the HTF flow-rate as the manipulated variable. In days with high Direct Normal Irradiance (DNI) using the maximum flow may not be sufficient for keeping the field outlet temperature within limits. This may also occurs in the case of power limitations commanded by the Transmission System Operator (TSO). If the plant has a TES, energy excess could be diverted to the salt tanks temporarily until they are fully loaded. Otherwise the excess energy will be lost and the flow sill not be sufficient to keep the temperature within limits. In either case, a safety mechanism is necessary to prevent the fluid temperature from exceeding the established limits. For diphenyl oxide (DPO) and biphenyl mixture fluids such as Therminol VP1 or similar, this temperature is around $400{ }^{\circ} \mathrm{C}$. In commercial plants, this security strategy is based on partial or total collector defocusing, mainly in the fourth collector and based on temperature hysteresis, which, in general, causes oscillations in the loop outlet temperature and a large number of actions and number of degrees traveled by the collector. Model based predictive control (MPC) strategies, Gain Scheduling Generalized Model Predictive Control (GS-GPC) and state space MPC, were presented in Sánchez et al. (2018, 2019a) to control the outlet temperature of the third and fourth collectors of $50 \mathrm{MW}$ solar plants by defocusing. In Sánchez et al. (2020) a comparative analysis was carried out on the use of GS-GPC strategy for defocus control in collectors 3 and 4 with respect to the use of the same type of controller in the 4 collectors, showing that on certain occasions it will be necessary to defocus the four collectors in order to maintain the outlet temperature below the maximum allowed.

In this work, unlike the GS-GPC strategy applied in the four collectors in the previous work (Sánchez et al., 2020), a FF and GS-GPC hybrid control strategy applied to the different collectors is presented. It is proposed to apply a FF to the first three collectors of each loop with different control sampling times. The fourth collector, the last one in each loop, will have a GS-GPC controller to appropriately track the designated temperature set-point. A FF strategy will be applied to collectors 1, 2 and 3 to regulate the temperature around the set-point temperatures without the need for and exhaustive tracking. It will be seen how this can contribute to reduce the total number of defocus control actions of the entire loop as well as the number of traveled degrees. In Sánchez et al. (2020), temperatures set-points were fixed, which it may not be the optimal way to operate with defocus in all situations. In this work a further step is presented. It is proposed to add a higher level strategy to obtain the optimal set-point temperatures that should be applied to collectors 1, 2 and 3 by 
means of an optimization algorithm. The objective of this optimization level will be to calculate set-point temperatures for the first three collectors so that they help keep the controller of the fourth collector in a safe authority control zone to be able to act against strong disturbances since it is the last collector of each loop. Therefore, a dynamic optimization of the defocus temperatures of collectors 1,2 and 3 is proposed, which will also avoid the loss of energy in loops with different parameters.

The paper is organized as follows: A brief description of previous work is presented in Section 2. In section 3 the model of the $50 \mathrm{MW}$ plant and mathematical models are presented. Section 4 briefly describes the GS-GPCs controller for defocus and power control. Section 5 presents the FeedForward controllers applied to collectors 1, 2 and 3 as well as its simulations results. The dynamic set-point temperature optimization algorithm, which is added to the FeedForward controller strategy as a final control scheme, is presented in Section 6. In Section 7 the different simulations of the final proposed scheme, numerical results and comparison between the different strategies are presented. Finally, the papers draws to and end in Section 8 with some conclusions.

\section{Related work}

In previous works, (Sánchez et al., 2018, 2019a), different MPC strategies were presented to control the outlet temperature of the solar field of a $50 \mathrm{MW}$ plant by defocusing the third and fourth collectors. However, collector defocusing is a safety mechanism that should only be applied in cases where the plant flow is not capable of controlling the outlet temperature (maximum flow rate reached) or when the plant is under power limitations. Two control strategies were proposed. One using a GS-GPC and the other using a state space based MPC which showed slightly better results. However, the GS-GPC strategy is simpler to carry out since it does not require observers or adaptation of all the parameters of the system matrices to the point of operation.

The are situations in which defocusing only two collectors will not be enough to prevent the output temperature of the solar field from exceeding the maximum allowable given by the manufacturer and avoid degradation. In Sánchez et al. (2020) an analysis of the GS-GPC control strategy applied to two and four collectors was performed. Comparisons of the use of controllers in two stages and four stages were presented, clearly observing that with two collectors it would not be possible to control the outlet temperature in cases of saturation when solar radiation is high. In addition, it was observed how the use of collectors 1 and 2 can greatly help to maintain defocus performance levels so that the actuators are in areas where the level of control authority is higher. This is beneficial since having the actuators in areas where they still have the ability to control can help to reject disturbances, whereas if the controller is close to the saturation zone of the control action, it could not cope with strong disturbances. It was concluded that the GS-GPC control strategy applied to the four collectors does not have to be active always, being able to coexist together with the defocus control of, only, the third and fourth collectors and through an event based system, the controller moves from a two-stage strategy to a fourth-stage as needed. Moreover, it was also commented that the set-points of fixed temperatures do not have to be optimal, except in the fourth collector where the margin is very narrow $\left(393-400{ }^{\circ} \mathrm{C}\right)$ and the nominal outlet temperature is $393{ }^{\circ} \mathrm{C}$.

In this work, the controllers and results applied to the four collectors will be presented and compared with respect to the previous work in which GS-GPCs controllers were applied to the four collectors (Sánchez et al., 2020). However, this study could also be carried out using other controllers such as MPC in the state space, although as already mentioned, it would require a more complex implementation when programming in a PLC due to the need of using state observers and adaptation of all the parameters of the matrices of the systems of each of the loops.

\section{3. $50 \mathrm{MW}$ solar plant model}

This section briefly describes the $50 \mathrm{MW}$ plant used, (Sánchez et al., 2018, 2019b). Two mathematical models, a distributed parameter model and a concentrated parameter model, are used for simulation purposes and controller design.

\subsection{Parabolic trough field}

The plant to be simulated will consist of a $50 \mathrm{MW}$ PTC CSP. These plants usually occupy about 110 hectares. In particular, the simulated plant consists of 90 loops of 600 meters in length each. Each of the loops is divided into four collectors (NREL Guzmán, 2017; NREL Helios, 2013; NREL Solaben, 2017).

Although the collectors of commercial plants can be from different companies, in general, they will have similar parameters. For the simulated plant, the collector EuroTrough ET150 will be used, which has similar characteristics to those used in $50 \mathrm{MW}$ parabolic trough solar plants. The other main element of the loops is the receiver tube. For this work, the Schott PTR 70 , a tube widely used in solar commercial applications, has been used. The main characteristics of this collector and the receiver tube that will be used for the plant model are shown in Table 1 (Geyer et al., 2002; Kearney, 2007; System Advisor Model (SAM). NREL, 2018; Burkholder et al., 2007; SCHOTT Solar CSP GmbH, 2020).

With regard to Heat Transfer fluid (HTF), Therminol VP1 is used as it is one of the most common in 50 MW parabolic trough solar plants with temperatures below $400{ }^{\circ} \mathrm{C}$, temperature from which it begins to degrade. It is important to emphasize that the parameters of the $\mathrm{HTF}$, such as kinematic viscosity $\mathrm{m}^{2} / \mathrm{s}(\nu)$, fluid density 
Table 1

EuroTrough ET150 and Receiver tube parameters.

\begin{tabular}{lll}
\hline Description & Value & Unit \\
\hline Focal length & 1.71 & $m$ \\
Aperture width & 5.77 & $m$ \\
Aperture area & 817.5 & $m^{2}$ \\
Number of Modules per Drive & 12 & Unitless \\
Length per Solar Collector Assembly (SCA) & 148.5 & $m$ \\
SCAs per loop & 4 & Unitless \\
Heat Collection Element (HCE) Type & Evacuated tube & Unitless \\
Collector reflectivity & 0.92 & Unitless \\
Collector form factor & 0.96 & Unitless \\
Receiver tube & Schott PTR70 & - \\
Receiver tube metal type & DIN 1.4541 & - \\
Receiver tube efficiency & 0.9 & Unitless \\
Receiver tube external diameter & 77 & mm \\
Receiver tube internal diameter & 66 & mm \\
\hline
\end{tabular}

$$
\begin{aligned}
\nu(T) & =1 \times 10^{-6} \cdot e^{\left(\frac{544.149}{T+114.43}-2.59578\right)} \\
\rho_{f}(T) & =-0.90797 \cdot T+0.00078116 \cdot T^{2} \\
& -2.367 \times 10^{-6} \cdot T^{3}+1083.25 \\
k(T) & =-8.1947 \times 10^{-5} \cdot T-1.9225 \times 10^{-7} \cdot T^{2} \\
& +2.5032 \times 10^{-11} \cdot T^{3}-7.2974 \times 10^{-15} \cdot T^{4} \\
& +0.1377 \\
C_{f}(T) & =4.5904 \times 10^{-8} \cdot T^{4}-3.1536 \times 10^{-5} \cdot T^{3} \\
& +0.006498 \cdot T^{2}+2.3458 \cdot T+1500.8
\end{aligned}
$$

The power cycle of a $50 \mathrm{MW}$ plant is directly linked to the nominal operating point of the plant, this is, $393{ }^{\circ} \mathrm{C}$ at the output of the solar field and a return temperature of $293{ }^{\circ} \mathrm{C}$. Therefore, the thermal jump that occurs in the heat exchange stage between HTF and steam is in the range of $90-100{ }^{\circ} \mathrm{C}$. To produce $50 \mathrm{MW}$ with this thermal jump, it is necessary to calculate a maximum flow-rate that can circulate through the plant so as not to exceed said power, since the turbine is designed, generally, to produce that maximum electrical power. For the calculation of the maximum flow-rate the equation 2 is used (Sánchez et al., 2019b). In this equation the efficiency of the Rankine cycle $\left(\mu_{\text {Rankine }}\right)$ and the parasitic effects $\left(\mu_{\text {parasitic }}\right)$, have been approximated by 0.381 and 0.9 respectively (NREL Andasol, 2017; NREL Extresol, 2017; System Advisor Model (SAM). NREL, 2018). $Q$ is the flow-rate, $P$ is the electric power, $\Delta T$ is the thermal difference. The flow-rate is in $\mathrm{kg} / \mathrm{s}$ which can be converted to $\mathrm{m}^{3} / \mathrm{h}$ as $(Q \cdot 3600) / \rho_{f}$. For this work, a maximum plant flow of $3000 \mathrm{~m}^{3} / \mathrm{h}$ will be used.

$$
Q=\frac{P \cdot 10^{6}}{\Delta T \cdot C_{f} \cdot \mu_{\text {Rankine }} \cdot \mu_{\text {parasitic }}}
$$

\subsection{Distributed parameter model}

The distributed solar field dynamics can be described by a partial differential equations (PDE) system shown in equation 3 . The system energy balance is described in this set of PDEs (Carmona, 1985; Camacho et al., 1997):

$\rho_{m} C_{m} A_{m} \frac{\partial T_{m}}{\partial t}=I K_{o p t} n_{o} G-H_{l} G\left(T_{m}-T_{a}\right)-L H_{t}\left(T_{m}-T_{f}\right)$

$\rho_{f} C_{f} A_{f} \frac{\partial T_{f}}{\partial t}+\rho_{f} C_{f} q \frac{\partial T_{f}}{\partial x}=L H_{t}\left(T_{m}-T_{f}\right)$

Subindexes $f$ and $m$ are used referring to the fluid and metal. Geometric efficiency depends on declination, day of the year, local latitude, collector parameters, solar hour and hourly angle. Coefficients and parameters $H_{l}$, specific heat $C$ and density $\rho$ depends on the temperature of the fluid. Coefficient $H_{t}$ depends on fluid temperature and HTF flow-rate (Camacho et al., 1997). An approximation for $H_{l}$ can be obtained from Burkholder et al. (2007), Lüpfert et al. (2008). To obtain $H_{t}$ value, equations (4) are used, where the dependency of the flow-rate can be observed.

$$
\begin{aligned}
& R e=Q \cdot D /(\nu \cdot A) \\
& \operatorname{Pr}=C_{f} \cdot \mu / k \\
& N u=0.025 \cdot\left(\operatorname{Re}^{0.79}\right) \cdot\left(\operatorname{Pr}^{0.42}\right) \cdot p h i \\
& H_{t}=N u \cdot k / D
\end{aligned}
$$

\subsection{Concentrated parameter model}

The concentrated parameter model (CPM) is a simplification of the spatially distributed solar field (Camacho et al., 2007, Gallego et al., 2019). This simplification provides an overall description of the solar field in terms of the fluid internal energy variation by equation 5 .

$$
\begin{array}{r}
C_{\text {loop }} \frac{d T_{\text {out }}}{d t}=\mu_{\text {col }} K_{\text {opt }} n_{o} S I- \\
-q C_{f} \rho_{f}\left(T_{\text {out }}-T_{\text {in }}\right) \\
-H_{l} S\left(T_{\text {mean }}-T_{a}\right)
\end{array}
$$

where $q$ is the HTF flow-rate, $T_{\text {out }}$ and $T_{\text {in }}$ are the outlet and inlet oil temperatures of the model, $T_{\text {mean }}$ is the average value between outlet and inlet temperatures and $T_{a}$ is the ambient temperature. $C_{\text {loop }}$ is the thermal capacity, approximated by $3.8 \times 10^{6} \mathrm{~J} /{ }^{\circ} \mathrm{C}, K_{\text {opt }}$ is the optical efficiency (mirror reflectivity, tube absorptance, and interception factor), $I$ is the direct solar irradiance and $S$ is the reflective surface of the loop, $3427 \mathrm{~m}^{2}$. And an added parameter, $\mu_{c o l}$, which is the collector efficiency based on the defocus curve, see Fig. 1.

\section{Generalized predictive control}

The GPC algorithm is based on the following singleinput single-output model (Camacho and Bordons, 2007): 


$$
A\left(z^{-1}\right) y_{k}=z^{-d} B\left(z^{-1}\right) u_{k-1}+\frac{C\left(z^{-1}\right)}{\Delta} e_{k}
$$

where $u_{k}$ and $y_{k}$ are the control and output sequences of the plant, $e_{k}$ is a zero mean white noise term and $\Delta$ is the integrator operator. $A, B$ and $C$ are polynomials in the backward shift operator $z^{-1} . d$ is the dead time of the system and $\Delta$ is the operator $1-z^{-1}$. This model is known as a Controller Auto-Regressive Integrated MovingAverage (CARIMA) model.

Consider a multistage cost function of the form:

$$
\begin{array}{r}
J\left(N_{1}, N_{2}, N_{u}\right)=\sum_{j=N_{1}}^{N_{2}} \delta(j)[\hat{y}(k+j \mid k)-w(k+j)]^{2} \\
+\sum_{j=1}^{N_{u}} \lambda(j)[\Delta u(k+j-1)]^{2}
\end{array}
$$

where $\hat{y}(k+j \mid k)$ is an optimum $\mathrm{j}$ step ahead prediction of the system output, $N_{1}$ and $N_{2}$ are the minimum and maximum costing horizons, $N_{u}$ is the control horizon, $\delta(j)$ and $\lambda(j)$ are weighting sequences and $w(k+j)$ is the future reference trajectory.

The minimum of the cost function can be obtained by setting the gradient of $\mathrm{J}$ equal to zero and solving the control sequence $\Delta \mathbf{u}$ by the following equation (Camacho and Bordons, 2007):

$$
\Delta \mathbf{u}=\left(\mathbf{G G}^{T}+\lambda \mathbf{I}\right)^{-1} \mathbf{G}^{T}(\mathbf{w}-\mathbf{f})
$$

where matrix $\mathbf{G}$ contains the step response coefficients of the forced response model (Camacho et al., 2012), I is the eye matrix, $\mathbf{f}$ is the free response of the plant, $\mathbf{w}$ is the future reference trajectory vector and $\lambda$ is the control weighting vector (Camacho and Bordons, 2007).

\subsection{Defocus GS-GPC Control}

The GS-GPC controller strategy design that is applied for collector defocusing can be found in Sánchez et al. (2018). This controller was designed based on the nonlinear defocus curve shown in Fig. 1 (Goswami et al., 2000). This curve presents 3 important zones. In two of the zones (0-1 and 4-5 degrees) the control actions to increase or decrease the efficiency of the collector must be high since these are zones with small slopes. However, the third zone (central zone around 2.5 degrees) shows a high slope. At this zone, small control actions will cause big changes in efficiency. In addition, it is important to note that beyond 3 degrees of defocus, the collector's efficiency drops below $20 \%$. Due to the non-linearity of the defocus curve and the fact that the main dynamics of the plant is governed by the flow-rate, the GS-GPC controller was designed using linear models at 9 defocus operation points $(0.5,1,1.5,2,2.5,3,3.5,4$ and 4.5 degrees) and 4 flow-rate operation points $\left(1494,1908,2322\right.$ and $\left.2736 \mathrm{~m}^{3} / \mathrm{h}\right)$.

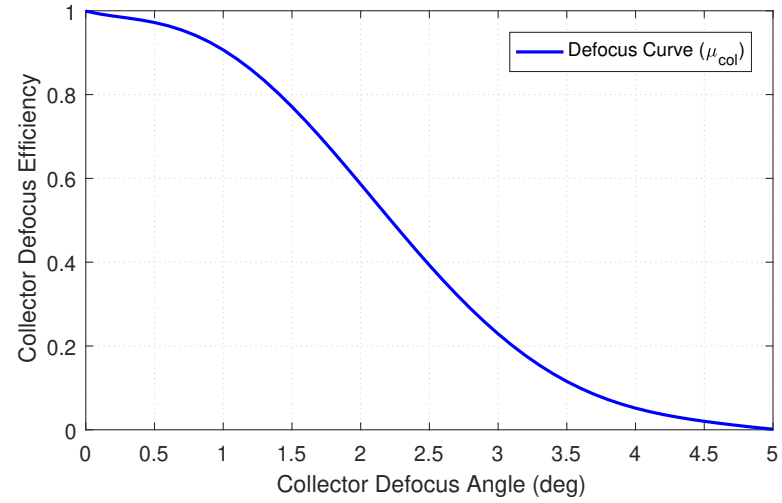

Figure 1 Collector efficiency-defocus angle curve.

\subsection{Power limitation GS-GPC control}

Commercial solar plants may receive power limitation orders from the TSO. This can be due to different causes, although, in general, it will be due to a saturation of the electrical network in the months of higher radiation such as autumn, summer and spring. The power limitation is mandatory and the plant has a time to reduce its electrical power to the set-point determined by the TSO.

For power control, a GS-GPC was designed as with the defocus controller, the reader is referred to Sánchez et al. (2018) for a full design description of this controller. To control the produced power the plant flow-rate is used as the manipulable variable and since the dynamics of the solar stage and the power cycle depend strongly on the flow-rate (Schenk et al., 2015; Montañés et al., 2018) the GS-GPC is designed using linear models at 3 different flowrate points to capture the non-linearity of the plant, approximately, and include it in the GPC: 167.06, 334.1 and $501.16 \mathrm{~kg} / \mathrm{s}\left(855,1710\right.$ and $\left.2565 \mathrm{~m}^{3} / \mathrm{h}\right)$.

\subsection{GS-GPC Defocus control: 1st, 2nd, 3rd and 4th col- lectors}

In a previous study the differences between using defocus control in two collectors and in four collectors were analyzed, all the controllers being GS-GPCs (Sánchez et al., 2020). It was observed that the use of more control stages (more collectors) provided, not only similar results in terms of loop outlet temperature tracking and safety level, but an action on the collectors in areas with a higher level of authority. On the other hand, when introducing a greater number of controllers, a greater number of actions was " incurred". Since GS-GPCs controllers were used, sampling times of 5 and 30 seconds were applied. These times provided a good tracking level of the set-point temperature, given the dynamics of the plant.

In Sánchez et al. (2020), the set-point temperatures of the first three collectors had a fixed value. This value was chosen based on the thermal jump (approx. $100{ }^{\circ} \mathrm{C}$ ) of a loop when the plant is operating at nominal temperature. The thermal jump was divided into four parts to distribute the defocus equally in the four collectors. However, this 373 374 375 376 377 
does not really have to be the optimal operation in all circumstances.

These controllers were tested under different conditions and against different disturbances: very high radiation day, high radiation with transients, significant disturbance in the inlet temperature and in case of power limitation. Furthermore, it was observed that the control with only two collectors was not sufficient in all situations.

\section{Feedforward defocus control 1st, 2nd and 3rd collectors}

In this work a modification of the defocus control scheme on the four collectors is proposed.

The use of a FF control strategy is mainly due to the simplicity of the controller itself and the static character of the controller. In previous works, model-based predictive controllers were proposed to control the collector outlet temperature by defocusing, tracking a reference temperature. However, exhaustive tracking of a set-point temperature on all collectors may not be strictly necessary. With the aim of trying to reduce the number of actions by applying the defocus in a distributed way in the four collectors, a FF control is proposed based on the concentrated parameter model 5. This controller is governed by Eq. 9 where $\mu_{c o l}$ is the efficiency of the collector, shown in 1.

$$
\mu_{c}=\frac{q C_{f} \rho_{f}\left(T_{r e f}-T_{i n-c}\right)+H_{l} S_{c}\left(T_{\text {mean }-c}-T_{a}\right)}{K_{o p t} n_{o} S_{c} I}
$$

Where $\mu_{c}$ is the collector defocus efficiency, $T_{i n-c}$ is the collector inlet temperature, $S_{c}$ is the collector reflective surface and $T_{\text {mean-c }}$ is the mean temperature between inlet and outlet collector temperatures. This controller will be applied to collectors 1,2 and 3 while the fourth will continue to maintain a GS-GPC model predictive control strategy, so that this collector will track the set-point temperature as it is the output of the system and is more important to avoid temperature limit safety.

In Sánchez et al. (2020) sampling times for the GSGPCs of 5 seconds (collector 4) and 30 seconds (collectors 1, 2 and 3) were used. Given that these controllers have the purpose of tracking a set-point, the sampling times in this type of controllers are linked to the dynamics of the system.

An advantage of the FF control is the possibility of increasing the sampling time easily without having to take into account the dynamics of the system since it is a steady state controller. For this work, a sampling time of 5 minutes was chosen for the first and second collectors. In this way, the first two collectors will be regulated so that the number of actions on the first two collectors can be reduced, but they will continue to be an aid to the defocus level of the fourth collector.

The FF control to be applied to the third collector will continue to maintain a sampling time of 30 seconds since it is the second most important collector in helping to reject radiation disturbances in order to avoid exceeding the limit temperature. However, this does not mean that this is the optimal sampling time for this controller.
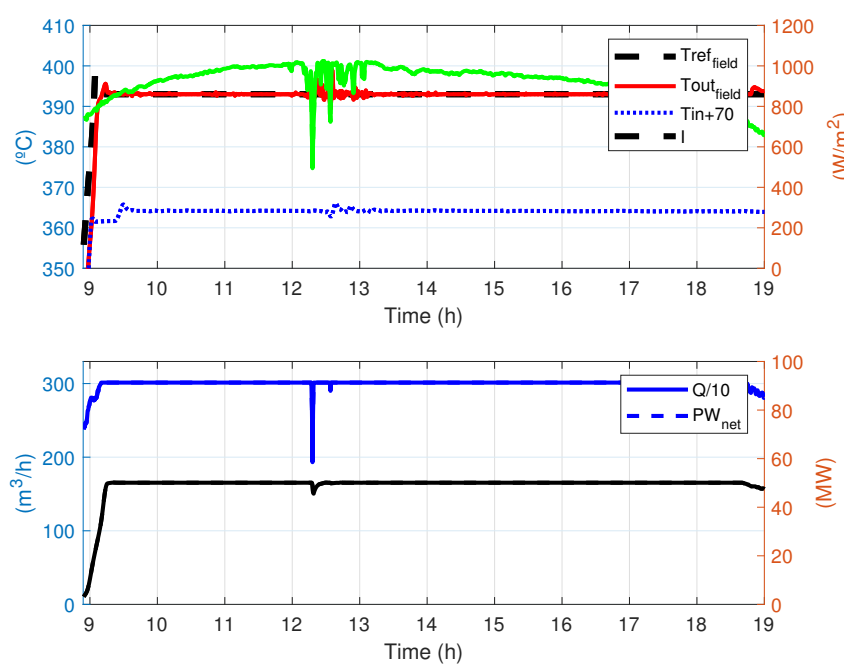

Figure 2 High radiation day with transients. FF Defocus (1st,2nd,3rd) and GS-GPCs (4th) (precision 0.1 degrees). Field and inlet temperatures, flow and power results.
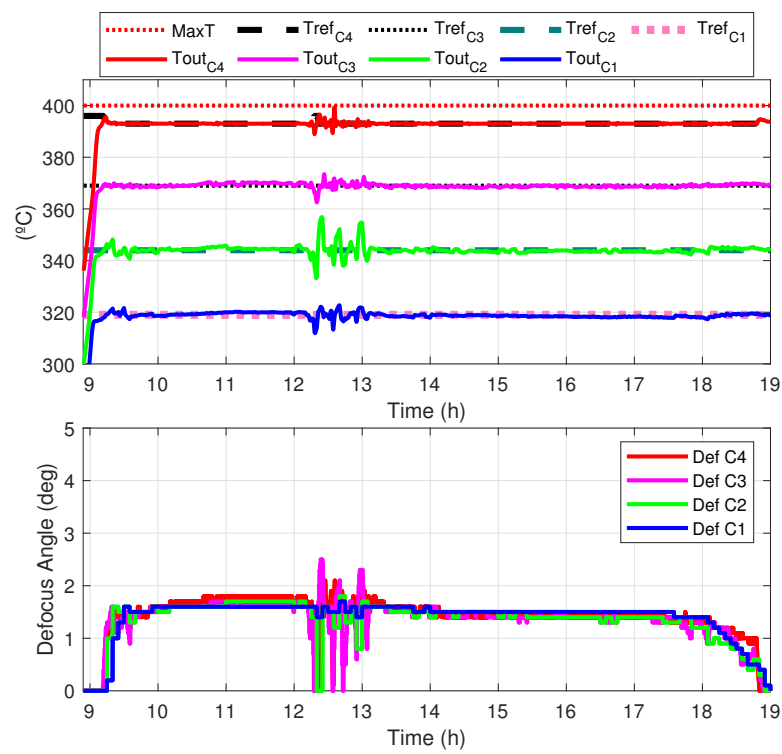

Figure 3 High radiation day with transients. FF Defocus (1st,2nd,3rd) and GS-GPCs (4th) (precision 0.1 degrees). Collectors temperatures and defocus actions.

The set-point temperatures for each of the loops remain the same as in the previous work, Sánchez et al. (2020), that is:

1. Temperature set-point collector 1: $319{ }^{\circ} \mathrm{C}$

2. Temperature set-point collector 2: $344{ }^{\circ} \mathrm{C}$ 
3. Temperature set-point collector $3: 369^{\circ} \mathrm{C}$

4. Temperature set-point collector $4: 393 / 396{ }^{\circ} \mathrm{C}$

A first example shows the simulation of the combination of the FF and the GS-GPC in the loops on a day of high radiation with transients. This scenario is shown in Figs. 2 and 3. It can be seen how between the flow and the defocusing actions it is possible to control the temperature correctly, rejecting the radiation disturbance.

It can be verified that collectors 1 and 2 do not modify their control actions every 5 minutes despite having this sampling time. This is due to the static characteristic of the controller. Similarly, although the third collector FF has a sampling time of 30 seconds, it can be seen that the FF does not always change the control signal every 30 seconds, something that greatly benefits the actuator life of said collector. Despite using an FF type controller, based on a compact model, the outlet temperatures of the collectors are kept within a small margin of error with respect to the set-point temperature.

\subsection{Inlet temperature disturbance rejection}

In this section, the proposed FF based control system applied at the first three collectors is simulated when there are significant disturbances in the inlet temperature of the solar field. It is important to try to reject such disturbances, as much as possible, before they reach the fourth collector to help it to keep a good track of the outlet solar field reference temperature. It is important to emphasize that if there are significant fluctuations in the solar field outlet temperature, these will return to the field inlet, although somewhat filtered and delayed, so the system will have to face these oscillations again.
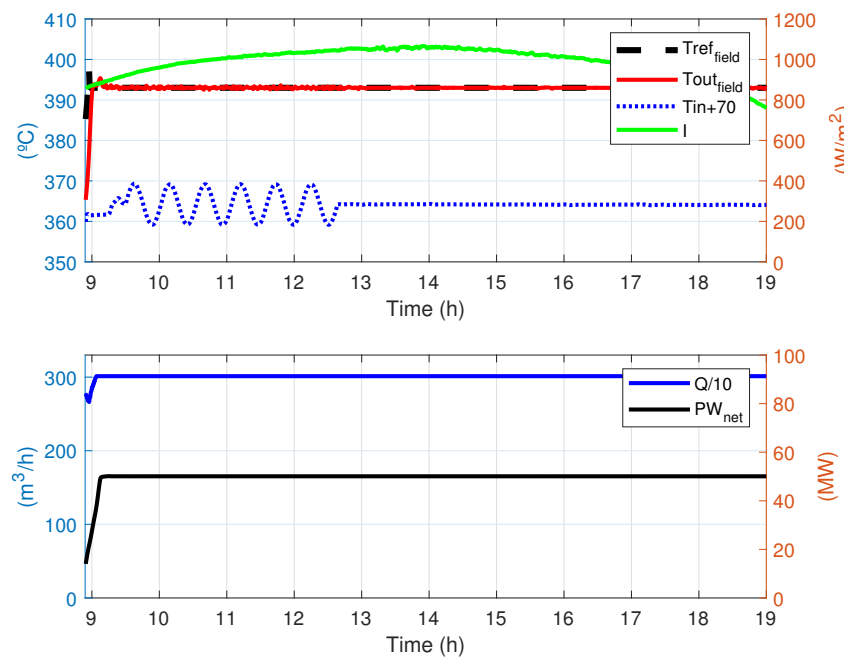

Figure 4 Inlet temperature disturbance. FF Defocus (1st,2n,3rd) and GS-GPCs (4th) (precision 0.1 degrees). Field and inlet temperatures, flow and power results.

The disturbance added to the inlet temperature is a 10 utes approximately (Sánchez et al., 2020). This scenario is presented in figures 4 and 5 . Observing these figures, it is verified even when sampling at 5 minutes, the FF controller of the first and second collectors become the main actors in rejecting this disturbance.
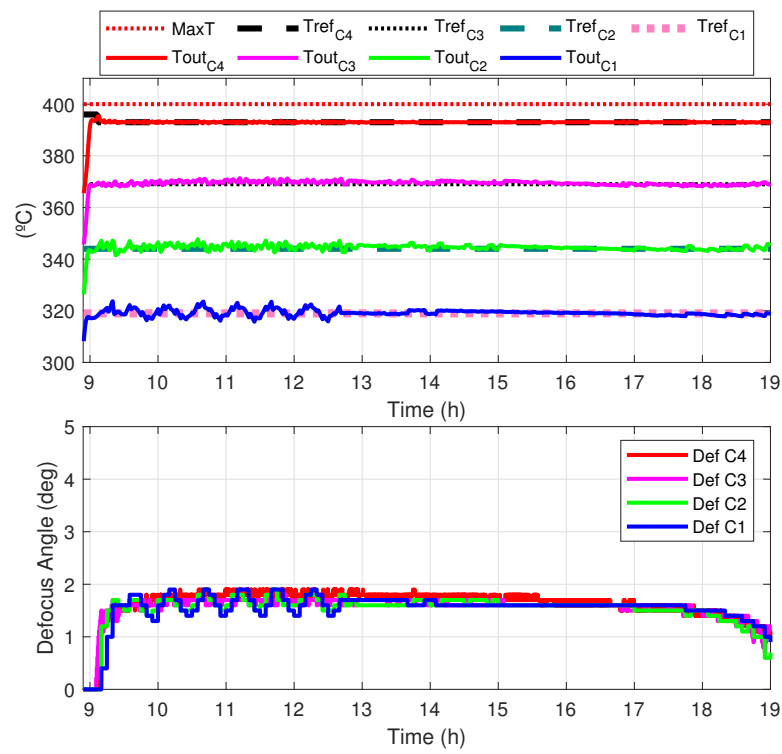

Figure 5 Inlet temperature disturbance. FF Defocus (1st,2n,3rd) and GS-GPCs (4th) (precision 0.1 degrees). Collectors temperatures and defocus actions.

\section{2. $30 \mathrm{MW}$ Power limitation}

The next simulated scenario, in which the operation of the FF controllers is going to be verified, is when a 30 MW power limitation appears. This scenario is shown in figures 6 and 6 .
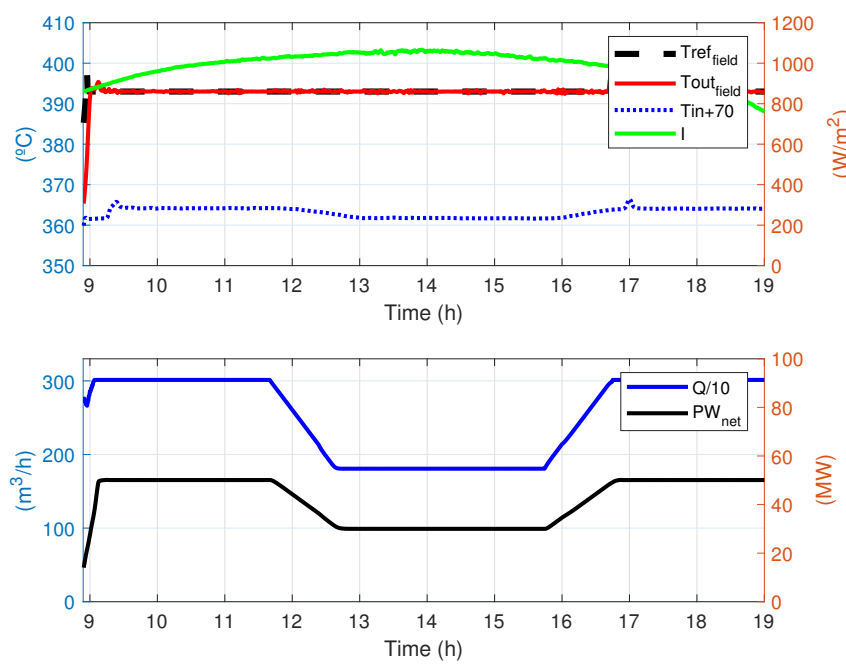

Figure 630 MW power limitation. FF Defocus (1st,2n,3rd) and GSGPCs (4th) (precision 0.1 degrees). Field and inlet temperatures, flow and power results. 
As in previous cases, the FF controller of the first two collectors has a good performance, maintaining the temperature in an area close to the set-point. It is verified again that it is not really necessary to carry out an exhaustive tracking of the set-point temperatures in the first and second collector, being only the fourth collector the designated collector in set-point tracking. Meanwhile, the others will be the help to avoid saturating the defocus (working in areas of little control authority).
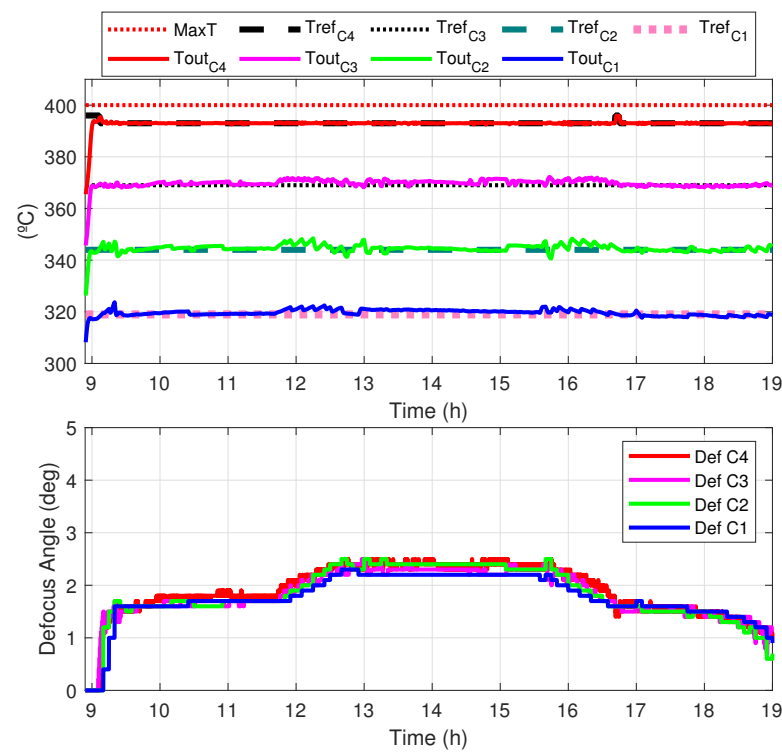

Figure $730 \mathrm{MW}$ power limitation. FF Defocus (1st,2n,3rd) and GS-GPCs (4th) (precision 0.1 degrees). Collectors temperatures and defocus actions.

\section{Collectors temperature set-point optimization}

Both, in the previous work, (Sánchez et al., 2020), and in the presented results of the FF controller, the temperature set-points of the collectors 1,2 and 3 have been kept constant at 319,344 and $369{ }^{\circ} \mathrm{C}$ (based on the thermal jump of the loop). However, maintaining these temperatures at constant values do not have to be the optimal way to control the collectors.

In this work, a model-based optimization to obtain the optimal reference temperatures for the defocus controllers is proposed. A multi-objective function, where the manipulated variables will be the defocus efficiency of the collectors, will be applied.

The idea is to obtain the temperature set-points necessary from the first 3 collectors so that several objectives are met:

1. The outlet temperature is kept in a close area around the set-point.

2. The defocus control action of the fourth collector is always below 2.2 degrees (hard constraint).
3. The defocus control actions of the first, second and third collector are below 2.2 degrees, as far as possible (soft constraint).

4. Penalize the defocus actions of collectors 1,2 and 3 , so that it only acts when necessary.

The cost function to be minimized is presented in equation (10).

$$
\begin{array}{ll}
\min _{\mu_{i}} J=\left(T_{\text {RefC4 }}-T_{\text {out }-C 4}\right)^{2}+\lambda_{3}\left(1-\mu_{3}\right)+\lambda_{2}\left(1-\mu_{2}\right)+ \\
\quad \lambda_{1}\left(1-\mu_{1}\right)+\delta_{3} S C_{3}+\delta_{2} S C_{2}+\delta_{1} S C_{1} \\
\text { s.t }: \\
\quad \mu_{4}>=\mu_{\min -C 4} \\
\quad \mu_{\min }<\mu_{i}(t+j)<\mu_{\max } \\
\quad x=g(x, U), y=f(x)
\end{array}
$$

$T_{\text {RefC4 }}$ and $T_{\text {out-C4 }}$ are the set-point temperature for the fourth collector and the outlet temperature of the fourth collector. $\mu_{i}$ are the collectors' defocus efficiencies. The variables $S C_{1}, S C_{2}$ and $S C_{3}$ refer to the soft constraints applied in the cost function. These variables will be zero if the constraints are not exceeded and will take value otherwise. $\lambda_{i}$ and $\delta_{i}$ are the weights.

For the optimization process, the concentrated parameter model will be used for two reasons. The first is because when applying the FF controller, the temperature set-point will not be exhaustively tracked. With the concentrated parameter model, even being an approximate global model, will be more than enough to obtain a setpoint temperature suitable for the collectors. The second is due to the computation time.

$$
\begin{aligned}
C_{c} \frac{d T_{o c}}{d t} & =\mu_{c} K_{o p t} n_{o} S_{c} I-q C_{f} \rho_{f}\left(T_{o c}-T_{i n-c}\right) \\
& -H_{l} S_{c}\left(T_{\text {mean }-c}-T_{a}\right)
\end{aligned}
$$

The concentrated parameter model is used for each of the collectors, Eq. (11), in order to obtain the temperature set-point in each of them, where $T_{o c}$ is the outlet temperature of the collector. However, the steady-state concentrated parameter model (ss-cpm), Eq. (12), is used since otherwise the models would have to be computed iteratively every certain time interval. In this way, it is based on the increase in temperature that occurs in each collector and, although it is an approximation in steady state, the approximated temperatures that meet the objective function and provide an appropriate defocus level can be obtained. The algorithm is described bellow. Filtering of the obtained temperature set-points is applied for its application in a smooth way, since it can vary considerably between iterations due to the static character of the model used for optimization. 


$$
\begin{aligned}
T_{o c} & =\frac{\mu_{c} K_{o p t} n_{o} I S_{c}-H l S_{c}\left(T_{\text {mean }-c}-T_{a}\right)}{q_{\max } C_{f} \rho_{f}} \\
& +\frac{q_{\max } C_{f} \rho_{f} T_{i n-c}}{q_{\max } C_{f} \rho_{f}}
\end{aligned}
$$

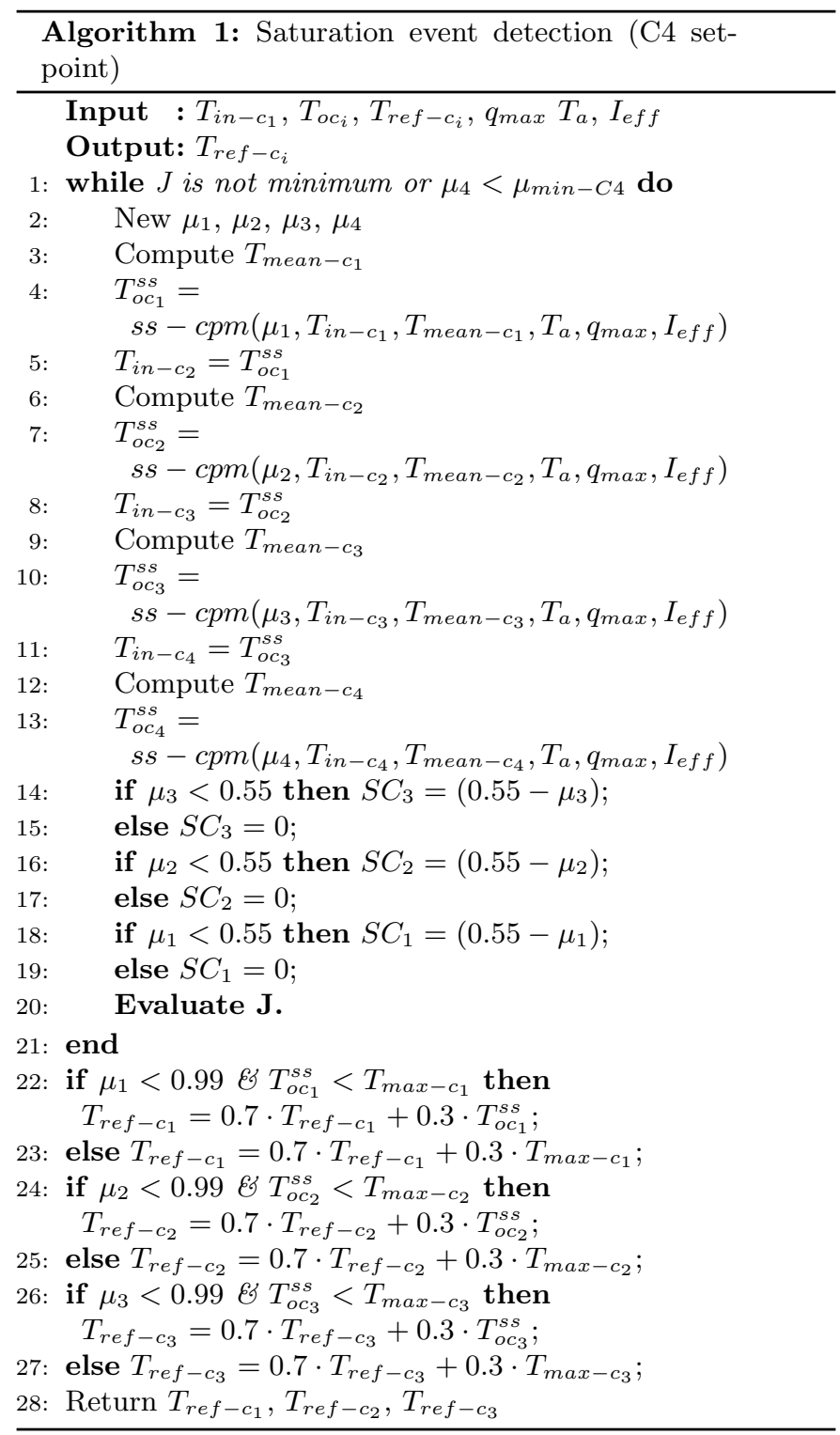

Notice that the variables used in the optimization are the collector efficiencies $\left(\mu_{1}, \mu_{2}, \mu_{3}\right.$ and $\left.\mu_{4}\right)$. This is done to avoid performing defocus angle conversion to efficiency within the algorithm. Once the efficiencies of the three collectors that minimize the objective function are obtained, the outlet temperatures of each of the collectors are extracted, as a result of the optimization. These will be the temperature set-points that will be applied to the FF controllers. For the process of obtaining these temperatures, the current flow is not assumed, but the maximum that could be. This is done to avoid unnecessary defocusing of the collectors. That is to say, if with the maximum flowrate flowing it is not necessary to defocus the collectors, it is evident that the fourth collector will have the capacity to act more than enough if needed. However, in cases of power limitation, the flow-rate that the GS-GPC power controller is generating must be used, since in these cases the flow-rate is forced, and as already presented in Sánchez et al. (2020), several collectors will be needed to cope with flow drops. The complete control scheme with the hierarchical optimization level to obtain the optimal temperatures for defocusing collectors (1,2 and 3$)$, the event based system for power limitations and the fourth collector setpoint event based system, is shown in Fig. 8.

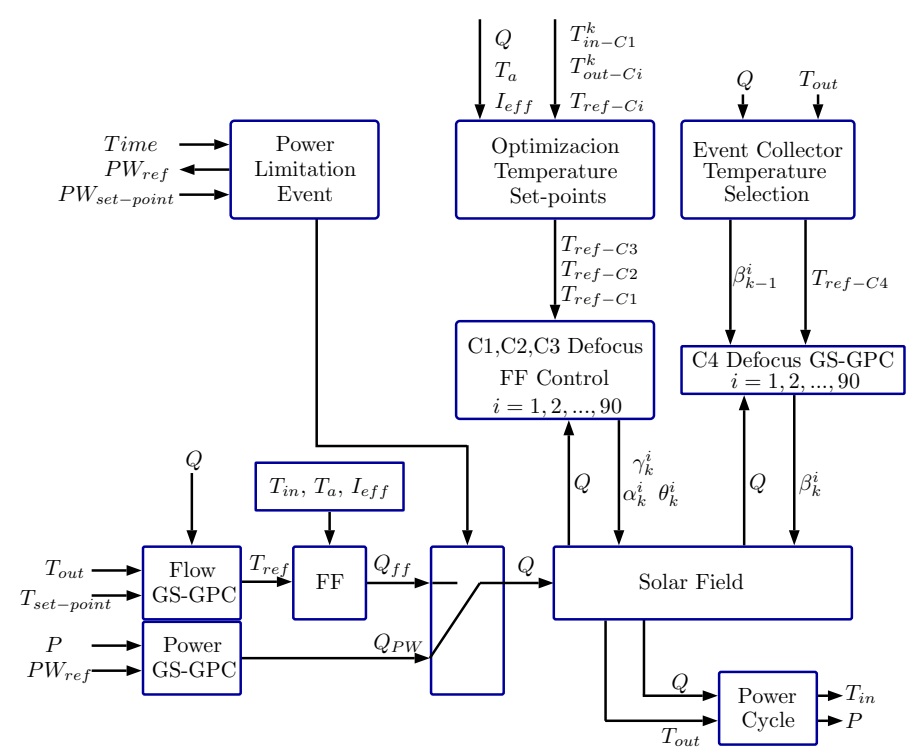

Figure 8 Hierarchical Temperature Set-point Optimization for defocusing and FF plus GS-GPC controllers for defocus control.

The variable $I_{\text {eff }}$ is the effective radiation $\left(I_{e f f}=\right.$ $\left.K_{\text {opt }} n_{o} I\right)$. The constraint to be applied to the fourth collector, $\mu_{4}>=\mu_{m i n-C_{4}}$ in (10), is such that the defocus efficiency of the fourth collector is not below $50 \%$. This would imply that $\mu_{4}>=0.5$. However, due to the inaccuracies made in the optimization process with the steady state CPM in series of the four collectors, the sampling time of 10 minutes between each optimization and the sampling time of 5 minutes of the FF controllers, this value has been increased so that the desired condition is approximately fulfilled in all cases. For this case the chosen value for this constraint is $\mu_{4}>=0.55$. The chosen values of the weights and parameters of the objective function and algorithm are as follows: $\lambda_{1}=300, \lambda_{2}=100, \lambda_{3}=50, \delta_{1}=50$, $\delta_{2}=400, \delta_{3}=500, T_{\max -c_{1}}=340, T_{\max -c_{2}}=376$ and $T_{\max -c_{3}}=385$. The values of the weights are chosen so that the control actions of the collectors are successive as necessary, with the first collector being the least necessary. The maximum defocus temperatures are selected high to 
avoid unnecessary defocus actions and the algorithm will be in charge of decreasing this temperature progressively throughout the simulation if it considers it necessary. The following section shows the results of the simulations when applying the FF and the proposed optimization to obtain temperature set-points.

\section{Results}

This section presents the results of the proposed strategies (FF+GS-GPC and FF+GS-GPC plus the set-point temperature optimization) of the simulated scenarios (high DNI, transients, inlet temperature disturbance and power limitation) and the comparative with respect to the results obtained in the previous work.

\subsection{High DNI and transients}

Fig. 9 shows the results of the high radiation scenario with occasional transients. It is observed how the actions on the different collectors occur as they are really necessary to meet the hard constraint and, roughly, the soft constraint included in the objective function. The temperature of the third and second collector are no longer constant and change over time as the conditions change.
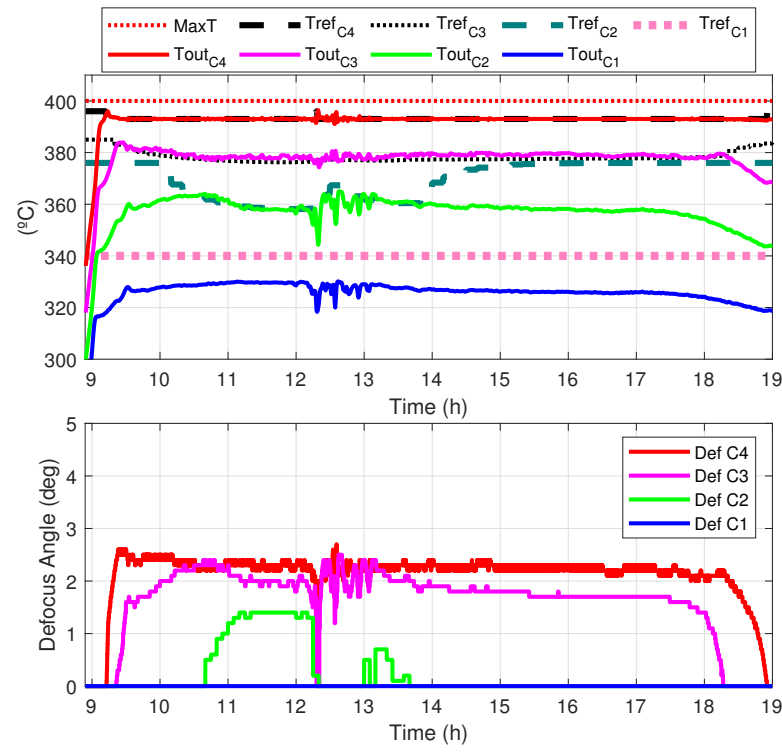

Figure 9 High radiation day with transients. Temperature set-point optimization. FeedForward Defocus (1st,2n,3rd) and GS-GPCs (4th) (precision 0.1 degrees). Collectors temperatures and defocus actions.

The tracking of the temperature set-point of the third collector drops as more action is needed to keep the fourth collector in the desired actuation range. The same happens with the set-point for the second collector. It decreases progressively until this collector is set out of focus for a short period, to assist the top two collectors. While the tracking temperature of the first collector remains high to keep it in focus since it is not necessary to defocus it to meet the objectives of the cost function.

\subsection{Inlet temperature perturbation rejection}

The behavior of the proposed strategy regarding a high disturbance in the inlet temperature is shown in Fig. 10. The sine wave added to the inlet temperature has the same characteristics as in Sánchez et al. (2020), that is, 10 degrees peak to peak and a period of 30 minutes. In this case the need for defocusing by the first collector is not observed unlike when fixed temperature set-points where used. The disturbance in this case is rejected by the second and third collector, arriving almost completely eliminated at the inlet of the fourth collector.
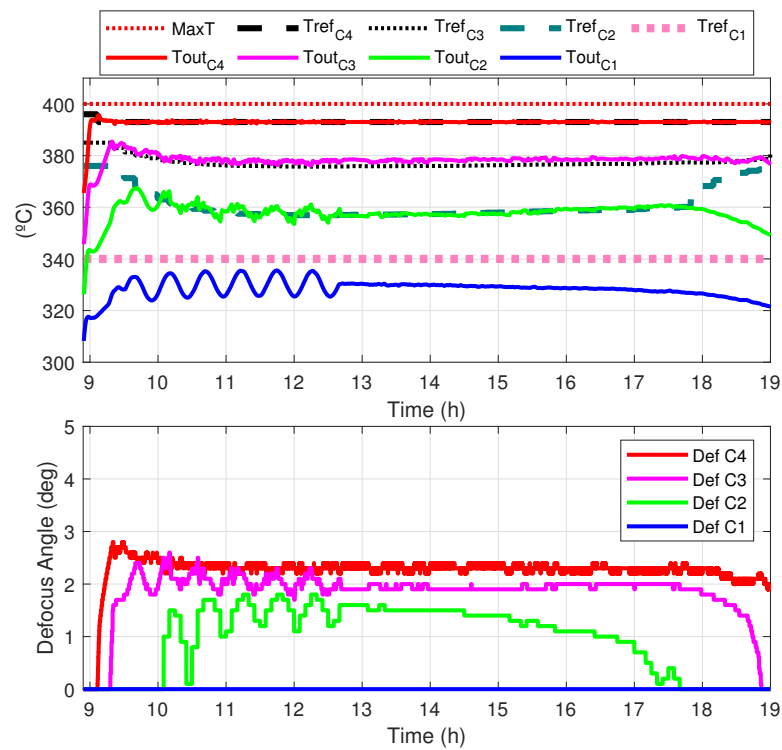

Figure 10 Inlet temperature disturbance. Temperature set-point optimization. FeedForward Defocus (1st,2n,3rd) and GS-GPCs (4th) (precision 0.1 degrees). Collectors temperatures and defocus actions.

\section{3. $30 \mathrm{MW}$ Power limitation}

It has been observed that the defocusing of the first collector is not usually needed, unlike if the temperature set-points are kept fixed in the four collectors. This is so due to the optimization that is performed and the cost function, which is designed mainly with the objective that the defocusing of the collectors come into action in order as needed to maintain the desired performance ranges.

A particularly interesting scenario is when there is a power limitation. The simulation, presented in Fig. 11, shows the simulation of the proposed strategy when there is a power limitation of $30 \mathrm{MW}$.

In Fig. 11 it is possible to see that the power objective is successfully met without problems in tracking both temperature and generated power. However, in order to maintain the outlet temperature, now the actuation of the first collector is necessary. The third collector and the second collector have two significant drops in their temperature set-points. The first is when they become necessary as in previous cases, and the second is when the power 

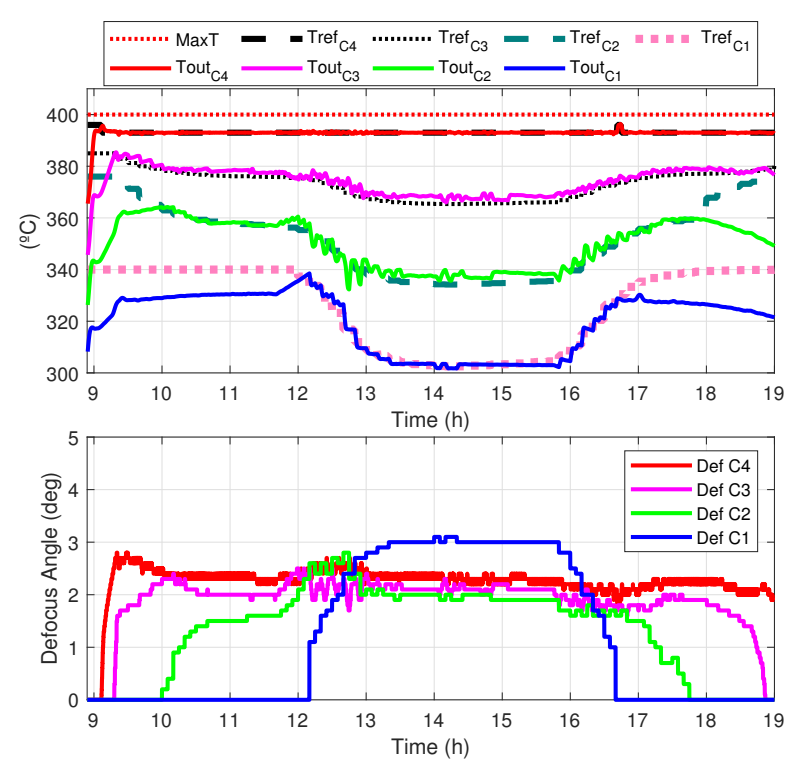

Figure $1130 \mathrm{MW}$ power limitation. Temperature set-point optimization. FeedForward Defocus (1st,2n,3rd) and GS-GPCs (4th) (precision 0.1 degrees). Collectors temperatures and defocus actions.

limitation is activated. Before de arrival of the power limitation, defocus control of the first collector is not necessary. Shortly after the power limitation event arrives, the set-point temperature of the first collector calculated by the algorithm decreases and therefore it defocus the first collector. But it only starts to defocus once the actions of the other three collectors is coming out of the interest strip. The temperature set-point for the first collector decreases until the other 3 collectors are back in the desired control zone. In this work, and as it can be deduced from the cost function, the first collector will be the last one in charge of keeping the previous collectors in the desired control area.

\subsection{Medium DNI}

The calculation of the optimal temperature set-points of each collector is not only relevant on days of high radiation where the flow is saturated. Since the optimization is carried out individually in each loop and is done dynamically throughout the day and the environmental conditions, it also extends to any other situation of the year.

Simulation, only with the FF, when the DNI is not too high is presented in Figs. 12 and 13, where one part of the day the plant works at maximum flow and in another part it is regulating flow-rate. It is observed that during a small part of the day where the flow is saturated, it is necessary to defocus. However, given the fixed set-points of temperatures it is clearly seen how all the collectors make movements in the collector actuators.

By applying the optimization algorithm for the dynamic calculation of the optimal temperatures for each collector, it can be concluded that in this case no collec- tor is necessary, except the fourth, to maintain a proper tracking of the outlet temperature, see Fig. 14.
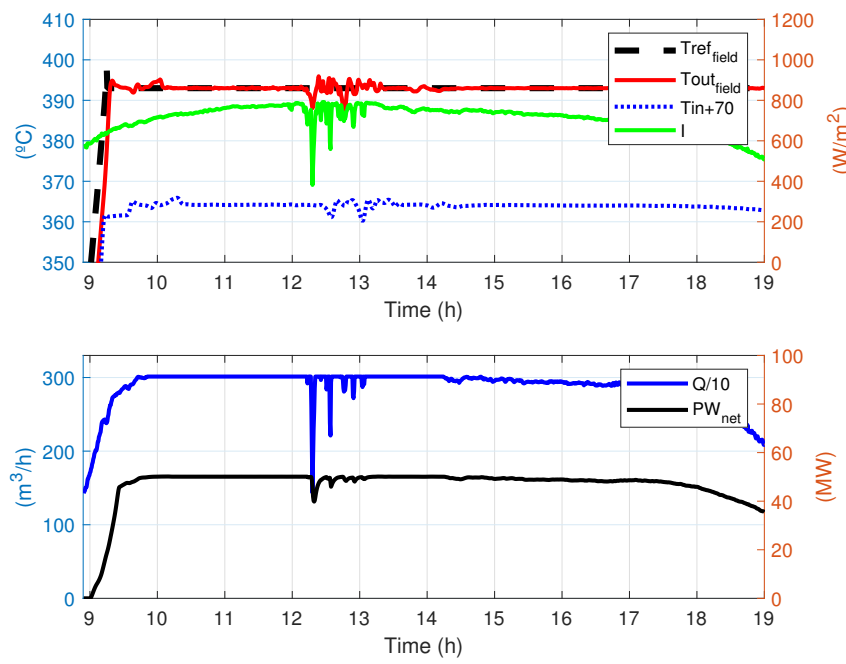

Figure 12 Medium DNI and 0.92 collectors reflectivity. FeedForward Defocus (1st,2n,3rd) and GS-GPCs (4th) (precision 0.1 degrees). Field and inlet temperatures, flow and power results.
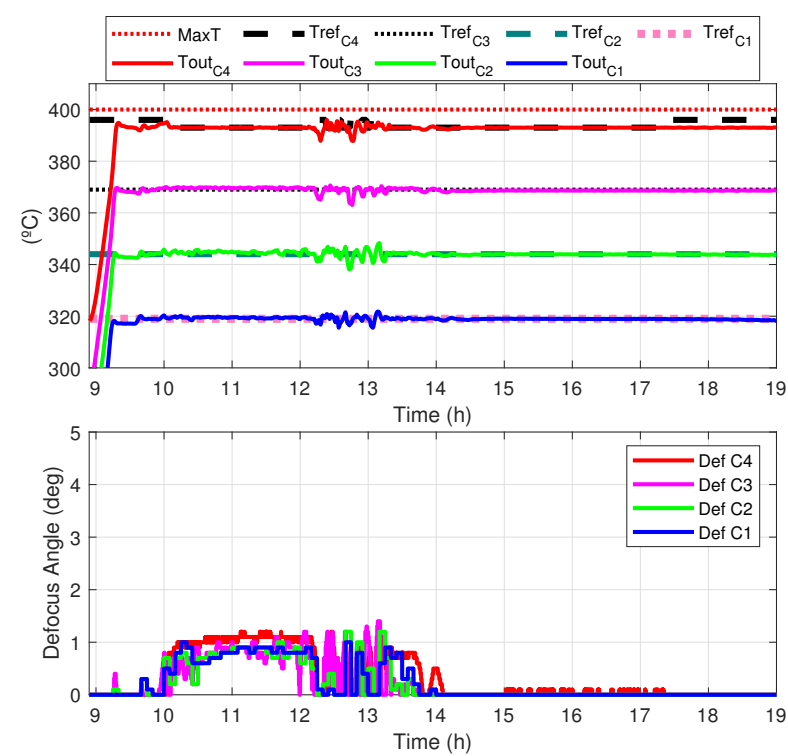

Figure 13 Medium DNI and 0.92 reflectivity (C3 C4). FeedForward Defocus (1st,2n,3rd) and GS-GPCs (4th) (precision 0.1 degrees). Collectors temperatures and defocus actions.

Applying the proposed strategy to optimize the temperature set-points of collectors 1, 2 and 3 is not only beneficial to avoid defocusing the collectors that are not necessary to meet desired objectives, but also to avoid possible energy losses.

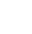



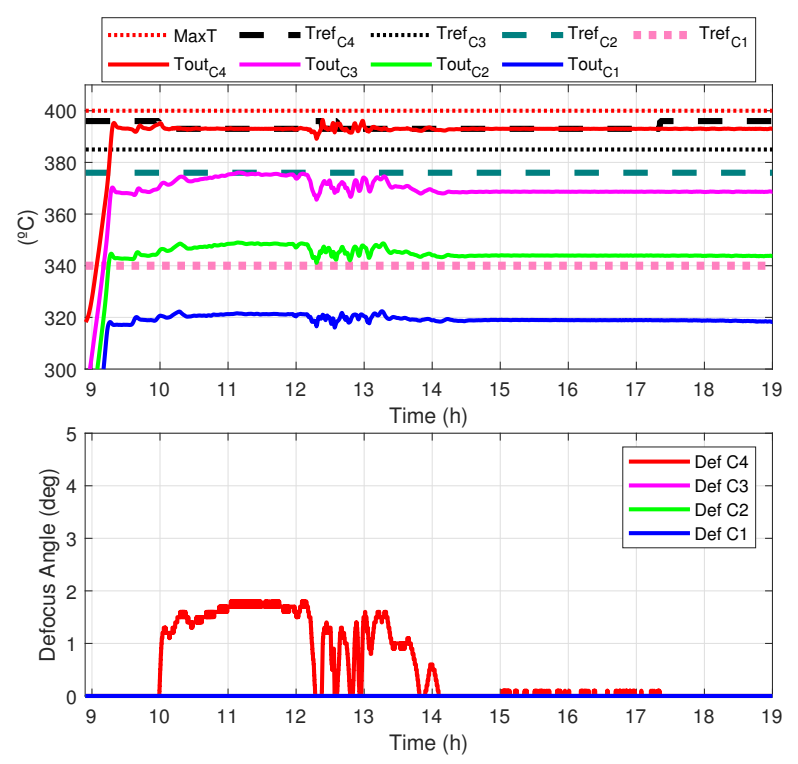

Figure 14 Medium DNI and 0.92 reflectivity (C1 C2 C3 C4). Temperature set-point optimization. FeedForward Defocus (1st,2n,3rd) and GS-GPCs (4th) (precision 0.1 degrees). Collectors temperatures and defocus actions.

The cases that have been shown were days with high
DNI in which the flow-rate was at its maximum. However, on days where the radiation is lower, the flow-rate will not be at its maximum and it should be, mainly, the main variable to control the field outlet temperature. Using fixed temperature set-points for collectors 1, 2 and 3 can cause unnecessary defocus actions, resulting in energy loss in some collectors. If energy is lost in collectors where should not be, will generally decrease the overall plant flow-rate. This fact was already mentioned in Sánchez et al. (2020), as coupling of temperature controllers by defocus and flow. An example is shown in which a $6 \%$ difference in reflectivity between collectors 1,2 and 3,4 . In this example, it will be observed how the use of the use of both GS-GPCs and FF controllers with fixed temperature set-points may cause energy losses compared to the calculation of temperature set-points dynamically by means of optimization.

Figs. 15 and 16 present the results when applying only the FeedForward, presented in section 5, with the temperature set-points for each of the collectors (1,2 and 3$)$ based on the distributed thermal jump $\left(319,344\right.$ and $\left.369^{\circ} \mathrm{C}\right)$. In this simulation it has been assumed that the first and second collectors have a reflectivity of 0.92 , while the third and fourth collectors have a reflectivity of 0.86 . The same simulation but adding the strategy to obtain the temperature set-points is presented in Figs. 17 and 18.

Figs. 15 and 17 show the global results of flow, power, radiation and field outlet temperature of both simulations. It can be seen that although the field outlet temperature is in nominal, the flow-rate in a part of the day is lower when applying only the FeedForward and is due to the use of fixed temperature set-points. This can be seen in
Figs. 16 and 18, where collector temperatures and defocus actions are shown for both simulations.
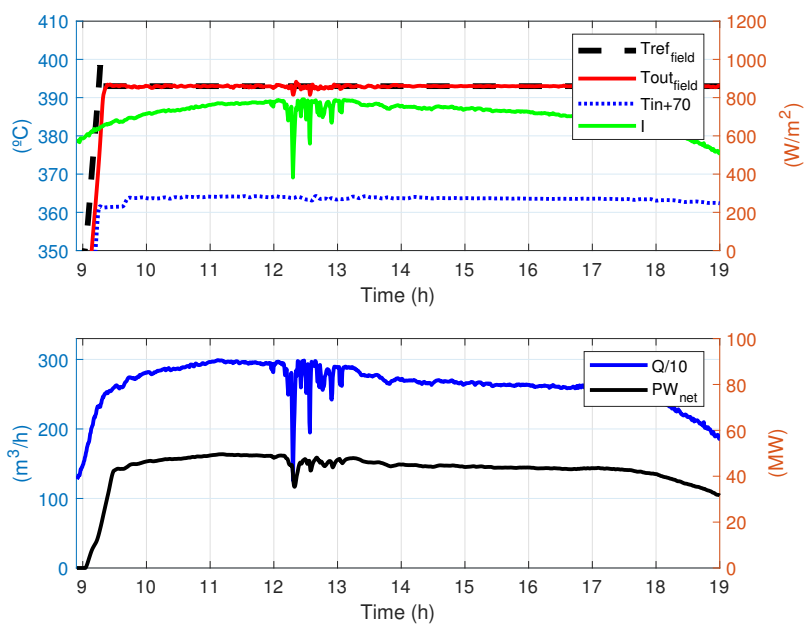

Figure 15 Medium DNI and 0.86 reflectivity (C3 C4). FeedForward Defocus (1st,2n,3rd) and GS-GPCs (4th) (precision 0.1 degrees). Field and inlet temperatures, flow and power results.


Figure 16 Medium DNI and 0.86 reflectivity (C3 C4). FeedForward Defocus (1st,2n,3rd) and GS-GPCs (4th) (precision 0.1 degrees). Collectors temperatures and defocus actions.

In Fig. 16 where the fixed set-points are used, it is observed that a defocus is maintained in the first, second and third collectors throughout the day. This is because the temperature set-point is low for these cases and energy is being lost in these collectors. Since the reflectivity of the third and fourth is somewhat lower, this loss of energy means that the first, second and third collectors will defocus before the fourth. However, the flow has not yet reached the maximum and the field outlet temperature is 
being regulated by flow. Losing energy in the first two collectors in this scenario causes the flow controller to be unable to add flow to the field.
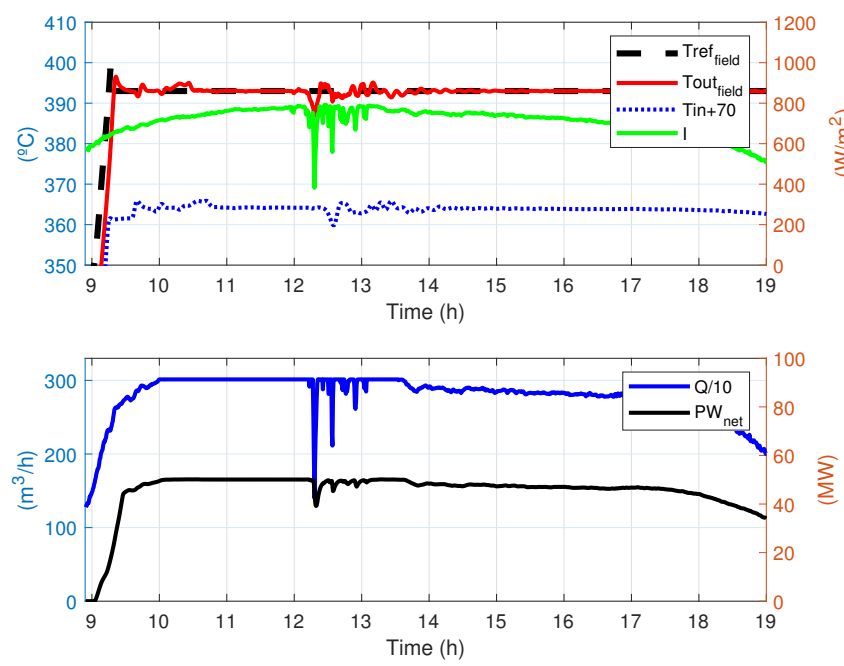

Figure 17 Medium DNI and 0.86 reflectivity (C3 C4). Temperature set-point optimization. FeedForward Defocus (1st,2n,3rd) and GSGPCs (4th) (precision 0.1 degrees). Field and inlet temperatures, flow and power results.
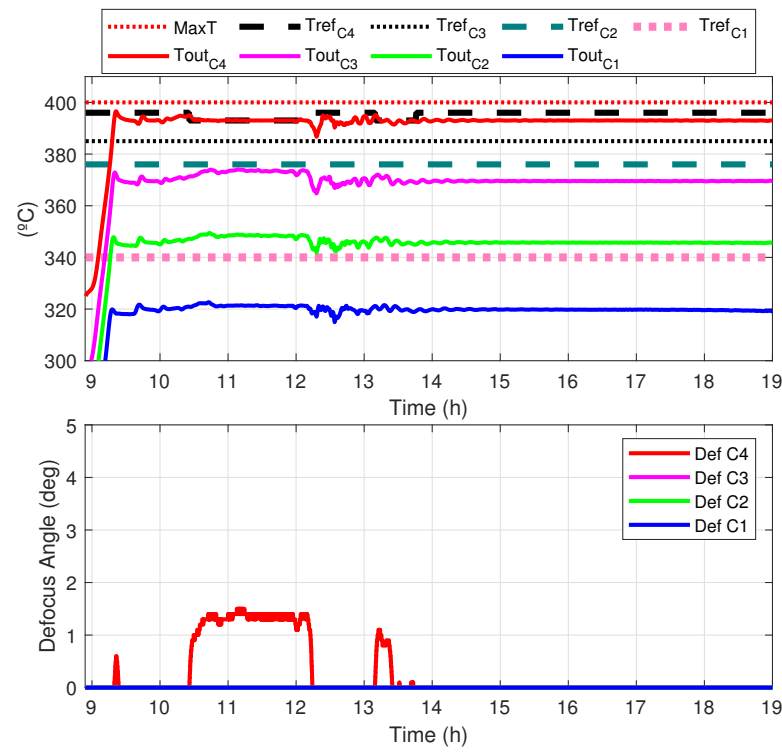

Figure 18 Medium DNI and 0.86 reflectivity (C3 C4). Temperature set-point optimization. FeedForward Defocus (1st,2n,3rd) and GSGPCs (4th) (precision 0.1 degrees). Collectors temperatures and defocus actions.

When applying the optimization for the dynamic calculation of the temperature set-points, see Fig. 18, the collectors only starts defocusing when they are strictly necessary to accomplish with the objectives of the cost function. Furthermore, it is observed that the only one that should defocus throughout the day is the fourth collector and it does so but only for a short period of time. This ensures that the global plant controller can use a higher flow-rate to regulate the field outlet temperature. This is shown in Fig. 17, where it is observed that the flow achieved by applying a variable temperature set-point for defocusing is greater and therefore the generated power of the plant is greater. In this case, a potential profit of $6.5 \%$ is obtained, see Table 7 .

Something important to take into account is the computation time of the algorithm since an optimization is being used to obtain the reference temperatures of the first three collectors of each of the loops of the plant. For this work, an Intel(R) Core(TM) i7-4790 CPU (3.60 GHz) with a RAM of $12 \mathrm{~GB}$ computer and the Matlab optimization toolbox (fmincon function) have been used. One of the advantages of the presented optimization algorithm is that it is not necessary to couple the entire plant. The optimization can be performed individually to each loop, resulting in 3-variable optimizations, which speeds up the process. The average measured computation time for a 90 loops solar plant is approximately 4.5 seconds. Taking into account that the chosen sampling time for the optimization is 10 minutes, the dynamic optimization proposed for obtaining the temperatures set-points of the first 3 collectors is much less than the optimization period and therefore feasible. Furthermore, if we extrapolate to plants with larger solar field surfaces like Solana with 808 loops, the mean time would be approximately around 40.4 seconds and it would still be a viable algorithm for implementation.

Tables 2, 3, 4, 5 and 6 present the results for each of the scenarios and the controllers, GS-GPC in all four collectors, GS-GPC in the fourth collector and FF controllers in collectors 1, 2 and 3, and finally, GS-GPC in the fourth collector and a FF control plus an optimization process for collectors 1, 2 and 3. These tables present several indicators: the number of defocus control actions in each collector, the total number of degrees traveled by each collector, total number of defocus actions and degrees of the loops, the average efficiency of the defocused collector and the control authority index. The control authority index is calculated using Eq. (13), (Sánchez et al., 2020). This is, a relation between the efficiency of the collector and the efficiency than can be modified by the collector when it moves 0.5 degrees more. This equation produces a curve which has been normalized with respect the point where the maximum value is reached, around 1.43 degrees and then modified (from 0 to 1.43 degrees (Sánchez et al., 2020)) to give it the sense of control authority as the control signal gets closer to the maximum but trying to maintain the non-linear relationship with the defocus curve, see Fig. 19.

$$
C I=e f f i c i e n c y \cdot a b s\left(e f f i c i e n c y-e f f_{+0.5^{\circ}}\right)
$$




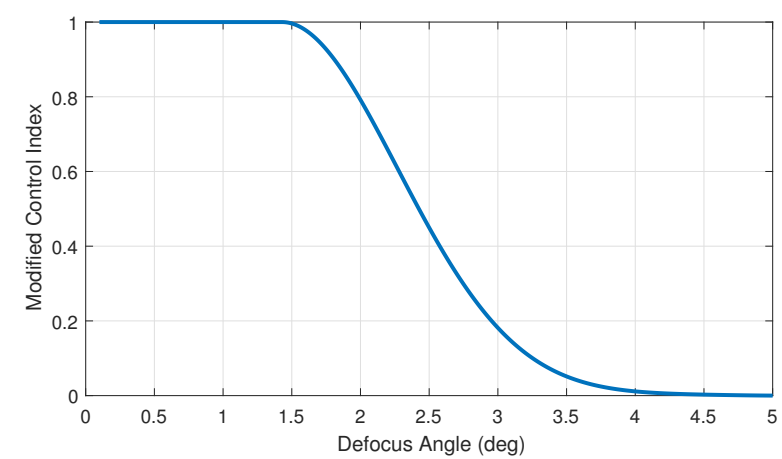

Figure 19 Modified Control Index curve (Sánchez et al., 2020).

Table 2

1 Loop results. High Radiation (9 am - 19 pm)

\begin{tabular}{|c|c|c|c|c|c|}
\hline Strategy & Collector & No. Actions & $\begin{array}{c}\text { Total } \\
\text { Degrees }\end{array}$ & $\begin{array}{c}\text { Mean } \\
\text { Efficiency }\end{array}$ & $\begin{array}{c}\text { Control } \\
\text { Authority }\end{array}$ \\
\hline & 1 & 407 & 40.8 & 0.76 & 0.99 \\
GS-GPC & 2 & 397 & 39.8 & 0.78 & 0.99 \\
& 3 & 402 & 40.3 & 0.77 & 0.99 \\
& 4 & 1385 & 138.5 & 0.73 & 0.98 \\
\hline & 1 & 2591 & 259.4 & - & - \\
\hline GS-GPC & 2 & 35 & 2.7 & 0.76 & 0.99 \\
FF & 3 & 110 & 11.9 & 0.77 & 0.99 \\
& 4 & 2326 & 232.6 & 0.73 & 0.99 \\
& All & 2484 & 252.5 & - & - \\
\hline & 1 & 0 & 0 & 1 & 1 \\
GS-GPC & 2 & 29 & 4.2 & 0.84 & 1 \\
FF & 3 & 84 & 9.6 & 0.62 & 0.84 \\
Optimal & 4 & 2215 & 221.5 & 0.48 & 0.61 \\
Set-points & All & 2328 & 235.3 & - & - \\
\hline
\end{tabular}

Table 3

1 Loop results. High Radiation/Transients (9 am - 19 pm)

\begin{tabular}{|c|c|c|c|c|c|}
\hline Strategy & Collector & No. Actions & $\begin{array}{c}\text { Total } \\
\text { Degrees }\end{array}$ & $\begin{array}{c}\text { Mean } \\
\text { Efficiency }\end{array}$ & $\begin{array}{c}\text { Control } \\
\text { Authority }\end{array}$ \\
\hline & 1 & 492 & 50.2 & 0.80 & 1 \\
GS-GPC & 2 & 489 & 51.2 & 0.82 & 1 \\
& 3 & 404 & 42 & 0.82 & 1 \\
& 4 & 1331 & 134 & 0.77 & 0.99 \\
\hline & 1 & 2716 & 277.4 & - & - \\
\hline GS-GPC & 2 & 52 & 5 & 0.80 & 1 \\
FF & 3 & 215 & 13.6 & 0.81 & 1 \\
& 4 & 2103 & 211.8 & 0.81 & 1 \\
& All & 2399 & 266.2 & - & 0.99 \\
\hline & 1 & 0 & 0 & 1 & 1 \\
GS-GPC & 2 & 21 & 5.8 & 0.91 & 1 \\
FF & 3 & 167 & 22.8 & 0.65 & 0.89 \\
Optimal & 4 & 1994 & 199.4 & 0.51 & 0.66 \\
Set-points & All & 2182 & 228 & - & - \\
\hline
\end{tabular}

Table 4

1 Loop results. Inlet Temperature Disturbance (9 am - 19 pm)

\begin{tabular}{|c|c|c|c|c|c|}
\hline Strategy & Collector & No. Actions & $\begin{array}{c}\text { Total } \\
\text { Degrees }\end{array}$ & $\begin{array}{c}\text { Mean } \\
\text { Efficiency }\end{array}$ & $\begin{array}{c}\text { Control } \\
\text { Authority }\end{array}$ \\
\hline & 1 & 435 & 43.6 & 0.76 & 0.99 \\
GS-GPC & 2 & 483 & 48.4 & 0.78 & 0.99 \\
& 3 & 402 & 40.3 & 0.77 & 0.99 \\
& 4 & 1226 & 122.6 & 0.73 & 0.98 \\
\hline & 1 & 2546 & 254.9 & - & - \\
\hline GS-GPC & 2 & 57 & 8.7 & 0.76 & 0.99 \\
FF & 3 & 154 & 8.5 & 0.77 & 0.99 \\
& 4 & 2020 & 202 & 0.76 & 0.99 \\
& All & 2277 & 235.5 & - & 0.97 \\
\hline & 1 & 0 & 0 & 1 & - \\
GS-GPC & 2 & 50 & 12.2 & 0.84 & 1 \\
FF & 3 & 172 & 19 & 0.61 & 0.84 \\
Optimal & 4 & 1861 & 186.1 & 0.48 & 0.61 \\
Set-points & All & 2083 & 217.3 & - & - \\
\hline
\end{tabular}

Table 5

1 Loop results. $30 \mathrm{MW}$ Power Limitation (9 am - 19 pm)

\begin{tabular}{|c|c|c|c|c|c|}
\hline Strategy & Collector & No. Actions & $\begin{array}{c}\text { Total } \\
\text { Degrees }\end{array}$ & $\begin{array}{c}\text { Mean } \\
\text { Efficiency }\end{array}$ & $\begin{array}{c}\text { Control } \\
\text { Authority }\end{array}$ \\
\hline & 1 & 505 & 50.6 & 0.67 & 0.92 \\
GS-GPC & 2 & 475 & 47.6 & 0.69 & 0.93 \\
& 3 & 394 & 39.5 & 0.68 & 0.92 \\
& 4 & 1347 & 134.7 & 0.64 & 0.87 \\
\hline & 1 & 2721 & 272.4 & - & - \\
\hline GS-GPC & 2 & 42 & 4.1 & 0.68 & 0.92 \\
FF & 3 & 156 & 16.5 & 0.66 & 0.91 \\
& 4 & 1942 & 194.2 & 0.63 & 0.90 \\
& All & 2167 & 221.3 & - & - \\
\hline & 1 & 24 & 6.4 & 0.35 & 0.37 \\
GS-GPC & 2 & 55 & 9.2 & 0.69 & 0.94 \\
FF & 3 & 188 & 20.4 & 0.60 & 0.80 \\
Optimal & 4 & 2011 & 201.1 & 0.49 & 0.62 \\
Set-points & All & 2278 & 237.1 & - & - \\
\hline
\end{tabular}

Table 6

1 Loop results. 0.86 Reflectivity C3 C4 (9 am - 19 pm)

\begin{tabular}{|c|c|c|c|c|c|}
\hline Strategy & Collector & No. Actions & $\begin{array}{c}\text { Total } \\
\text { Degrees }\end{array}$ & $\begin{array}{c}\text { Mean } \\
\text { Efficiency }\end{array}$ & $\begin{array}{c}\text { Control } \\
\text { Authority }\end{array}$ \\
\hline & 1 & 40 & 4.9 & 0.94 & 1 \\
GS-GPC & 2 & 54 & 9.1 & 0.90 & 1 \\
FF & 3 & 204 & 24.5 & 0.92 & 1 \\
& 4 & 0 & 0 & 1 & 1 \\
& All & 298 & 38.5 & - & - \\
\hline GS-GPC & 1 & 0 & 0 & 1 & 1 \\
FF & 2 & 0 & 0 & 1 & 1 \\
Optimal & 3 & 0 & 0 & 1 & 1 \\
Set-points & 4 & 406 & 40.6 & 0.86 & 1 \\
& All & 406 & 40.6 & - & - \\
\hline
\end{tabular}


Table 7

Mean Power Results. 0.86 Reflectivity C3 C4 (9 am - 19 pm)

\begin{tabular}{|c|c|c|c|}
\hline Control & $\begin{array}{c}\text { Mean Power } \\
(\mathrm{MW})\end{array}$ & $\begin{array}{c}\text { Mean Benefit } \\
(\mathrm{MW})\end{array}$ & $\begin{array}{c}\text { Mean Benefit } \\
(\%)\end{array}$ \\
\hline $\begin{array}{c}\text { GS-GPC } \\
\text { FF }\end{array}$ & 44.4357 & 0 & 0 \\
\hline $\begin{array}{c}\text { GS-GPC } \\
\text { FF } \\
\text { Optimal } \\
\text { Set-points }\end{array}$ & 47.2446 & 2.81 & 6.32 \\
\hline
\end{tabular}

In the results shown in the different tables, it can be observed how when using GS-GPC controllers in the four collectors, with fixed temperatures and control times mentioned in Section 5, the tracking of the temperature is actually distributed among the four collectors. That is, all four GS-GPC controllers are continuously rejecting disturbances with low sampling times. By applying the FF controller with sampling times every five minutes in the first three collectors, the tracking of the outlet temperature is returned almost completely to the fourth collector, which is responsible for maintaining the outlet temperature at its reference. This is easy to verify by comparing the results of the two strategies in the tables. It can be seen that in the case of the GS-GPC controller applied to the four collectors the number of actions on the fourth collector is less than when using the FF control on the first three collectors. Basically what is being done is to apply an aid control to the fourth collector in the first collectors with a longer actuation time, which will imply fewer actions in the first three collectors and it will be the fourth collector the one to properly track the outlet temperature. However, it can be seen that the total number of actions and degrees traveled when applying the FF control in the first three collectors is reduced compared to the case of the GS-GPC control in the four collectors.

However, as already mentioned in 6 , the temperature set-points for the first three collectors do not have to be fixed. That is, the optimal temperatures to defocus said collectors would be those that minimize the number of defocusing actions and degrees traveled, avoiding energy losses in the solar field and that also meet the wishes or the general state of the plant.

It can be observed, in the simulated scenarios, how the dynamic calculation of the set-point temperature for the collectors is different in each situation. Since the objetive is to minimize the cost function presented in (10), it will not be necessary to apply any defocus in the first collectors and for this, high set-point temperatures will be applied to the first three collectors to avoid defocus actions, as long as the constraints of the cost function established for the fourth collector are met. However, these set-point temperatures will be modified as the optimization computation detects that the fourth collector is going to exceed the imposed defocus constraints. This can be clearly seen in cases of high radiation or in the power limitation scenario, Figs. 11, 10 and 9.

By applying, at a higher level, the defocus temperature optimization strategy it is possible to further reduce the total number of defocus actions and degrees traveled of the entire loop. Moreover, as can be seen in the tables 2, 3, 4, 5 and 6 , the dynamic temperature set-points achieve keep the fourth collector GS-GPC controller at around $50 \%$ defocus efficiency, by introducing other collectors to defocus in order to help the fourth collector continue to maintain a good index of control authority.

\section{Conclusion}

In the control and optimization of CSP PTC plants, as well as in other types of CSP plants, it is important to consider various factors to optimize the complete plant process. Among others are, the tracking of the outlet temperature, maximizing the electrical power generated, complying with the power limitations and maximizing the life of the actuators, as far as possible, being in this case, the defocus actuators of the collectors. It is not always possible to keep the outlet temperature of the solar field below the maximum safety limits using only the flow-rate. Since its degradation would cause having to replace the HTF of the plant at a high cost it is necessary to use efficient controllers to defocus the collectors.

In this work, a FeedForward control strategy has been proposed for the first three collectors of each loop, while a GS-GPC is applied in the fourth collector. The fact of using FF strategies in the first collectors is to help the fourth collector to keep it in a zone with a good level of control authority to be able to cope with disturbances without being close to the saturation level of the actuator. In addition, a higher level has been proposed in the hierarchy of the defocus control in which an optimization is carried out for the calculation of the optimal set-point temperatures to defocus the first three collectors so that they only act as the level of fourth collector defocus efficiency is close to $50 \%$. It is shown how this optimization strategy helps to reduce the number of defocus actions and degrees traveled by the complete loop with respect to the strategy in which only the FF is applied in the first three collectors and when the four collectors have a GS-GPC. The optimization process applies defocus as desired by the cost function and as it has been verified, collectors 1,2 and 3 go into defocusing as necessary to meet the constraints of the cost function, starting with the third, then the second and finally the first collector if necessary. Furthermore, it has been shown how the optimization level for the dynamic calculation of set-point temperatures for the defocusing of the collectors allows to avoid energy losses in cases in which the state of the plant collectors differs and in which the use of fixed temperatures would cause energy losses. 


\section{Acknowledgments}

The authors would like to acknowledge the European Research Council for funding this work under Advanced Research Grant OCONTSOLAR (789051) and the VI Plan of Research and Transfer of the University of Seville (VI PPIT-US) under the contracts "Contratos de acceso al Sistema Español de Ciencia, Tecnología e Innovación para el desarrollo del programa propio de $\mathrm{I}+\mathrm{D}+\mathrm{i}$ de la Universidad de Sevilla".

\section{References}

Aguilar, R., Valenzuela, L., Avila-Marin, A. L., Garcia-Ybarra, P. L., 2019. Simplified heat transfer model for parabolic trough solar collectors using supercritical CO2. Energy Conversion and Management 196, $807-820$.

Blanco, M., Miller, S., 2017. 1 - Introduction to concentrating solar thermal (CST) technologies. In: Blanco, M. J., Santigosa, L. R. (Eds.), Advances in Concentrating Solar Thermal Research and Technology. Woodhead Publishing Series in Energy. Woodhead Publishing, pp. $3-25$.

Burkholder, F., Brandemuehl, M., Price, H., Netter, J., Kutscher, C., Wolfrum, E., 2007. Parabolic trough receiver thermal testing. In: Energy Sustainability, ASME 2007 Energy Sustainability Conference. pp. 961-970.

Camacho, E., Gallego, A., 2013. Optimal operation in solar trough plants: A case study. Solar Energy 95, $106-117$.

Camacho, E., Soria, M. B., Rubio, F., Martínez, D., 2012. Control of Solar Energy Systems, 1st Edition. Springer-Verlag London.

Camacho, E. F., Berenguel, M., Rubio, F. R., 1997. Advanced Control of Solar Plants. Springer Science \& Business Media.

Camacho, E. F., Bordons, C., 2007. Model Predictive Control, 2nd Edition. Springer-Verlag London.

Camacho, E. F., Rubio, F. R., Berenguel, M., Valenzuela, L., 2007. A survey on control schemes for distributed solar collector fields. part i: Modeling and basic control approaches. Solar Energy 81 (10), $1240-1251$

Carmona, R., 1985. Analisis, modelado y control de un campo de colectores solares distribuidos con sistema de seguimiento en un eje. Ph.D. thesis. Universidad de Sevilla.

Fenchouche, Z., Chakir, M., Benzineb, O., Boucherit, M. S., Tadjine, M., May 2017. Robust controller design for solar plant using extended coefficient diagram method ( $\mathrm{cdm}$ ) incorporating pid. In: 6th International Conference on Systems and Control (ICSC). pp. 348-353.

Gallego, A. J., Macías, M., de Castilla, F., Camacho, E. F., 2019. Mathematical Modeling of the Mojave Solar Plants. Energies $12(21)$.

Gallego, A. J., Yebra, L. J., Camacho, E. F., 2018. Gain Scheduling Model Predictive Control of the New TCP-100 Parabolic Trough Field. IFAC-PapersOnLine 51 (2), 475 - 480, 9th Vienna International Conference on Mathematical Modelling.

Geyer, M., Lüpfert, E., Osuna, R., Esteban, A., Schiel, W., Schweitzer, A., Zarza, E., Nava, P., Langenkamp, J., Mandelberg, E., 2002. Eurotrough - Parabolic Trough Collector Developed for Cost Efficient Solar Power Generation. In: 11th SolarPACES International Symposium on Concentrated Solar Power and Chemical Energy Technologies.

González-Roubaud, E., Pérez-Osorio, D., Prieto, C., 2017. Review of commercial thermal energy storage in concentrated solar power plants: Steam vs. molten salts. Renewable and Sustainable Energy Reviews 80, $133-148$.

Goswami, D., Kreith, F., Kreider, J., 2000. Principles of Solar Engineering, 2nd Edition. Taylor \& Francis.

Helioscsp.com News, 2018. Abengoa Dubai Concentrated Solar Power contract valued at $\$ 650 \mathrm{mn}$. http://helioscsp.com/abengoadubai-concentrated-solar-power-contract-valued-at-650mn/, (Accessed: 04 August 2020).
Karamali, M., Khodabandeh, M., 2017. A distributed solar collector field temperature profile control and estimation using inlet oil temperature and radiation estimates based on iterative extended kalman filter. Renewable Energy 101, $144-155$.

Kearney, D. W., 2007. Parabolic trough collector overview. Parabolic trough work-shop, NREL.

Li, L., Li, Y., He, Y.-L., 2020. Flexible and efficient feedforward control of concentrating solar collectors. Applied Thermal Engineering $171,115053$.

URL http://www.sciencedirect.com/science/article/pii/ S1359431119360661

Lima, D. M., Normey-Rico, J. E., Santos, T. L. M., 2016. Temperature control in a solar collector field using Filtered Dynamic Matrix Control. ISA Transactions 62, 39 - 49, sI: Control of Renewable Energy Systems.

Lüpfert, E., Riffelmann, K., Price, H., Burkholder, F., Moss, T., 2008. Experimental Analysis of Overall Thermal Properties of Parabolic Trough Receivers. Journal of Solar Energy Engineering 130 (2).

Merad, F., Labar, H., Samira KELAIAIA, M., Necaibia, S., Djelailia, O., 2019. A maximum power control based on flexible collector applied to concentrator solar power. Renewable and Sustainable Energy Reviews 110, 315 - 331 .

URL http://www.sciencedirect.com/science/article/pii/ S1364032119302977

Montañés, R. M., Windahl, J., Palsson, J., Thern, M., 2018. Dynamic Modeling of a Parabolic Trough Solar Thermal Power Plant with Thermal Storage Using Modelica. Heat Transfer Engineering 39 (3), 277-292.

NREL Andasol, 2017. Concentrated Solar Power Projects. Andasol 1. (Accessed: 04 August 2020).

URL https://solarpaces.nrel.gov/andasol-1

NREL Extresol, 2017. Concentrated Solar Power Projects. Extesol1. (Accessed: 04 August 2020).

URL https://solarpaces.nrel.gov/extresol-1

NREL Guzmán, 2017. Concentrated Solar Power Projects. Guzmán. (Accessed: 04 August 2020).

URL https://solarpaces.nrel.gov/guzman

NREL Helios, 2013. Concentrated Solar Power Projects. Helios I. (Accessed: 04 August 2020).

URL https://solarpaces.nrel.gov/helios-i

NREL PTC, 2020. Concentrating Solar Power Projects. Parabolic Trough Projects. (Accessed: 04 August 2020).

URL https://solarpaces.nrel.gov/by-technology/ parabolic-trough

NREL Solaben, 2017. Concentrated Solar Power Projects. Solaben 2. (Accessed: 04 August 2020).

URL https://solarpaces.nrel.gov/solaben-2

Peiró, G., Prieto, C., Gasia, J., Jové, A., Miró, L., Cabeza, L. F., 2018. Two-tank molten salts thermal energy storage system for solar power plants at pilot plant scale: Lessons learnt and recommendations for its design, start-up and operation. Renewable Energy 121, 236 - 248.

Pitz-Paal, R., 2018. Concept and status of Concentrating Solar Power systems. EPJ Web of Conferences 189.

Prieto, C., Rodríguez, A., Patiño, D., Cabeza, L. F., 2018. Thermal energy storage evaluation in direct steam generation solar plants. Solar Energy 159, $501-509$.

Roca, L., Bonilla, J., Rodríguez-García, M. M., Palenzuela, P., de la Calle, A., Valenzuela, L., 2016. Control strategies in a thermal oil - Molten salt heat exchanger. AIP Conference Proceedings 1734 (1), 130017.

Romero, M., González-Aguilar, J., 2014. Solar thermal CSP technology. Wiley Interdisciplinary Reviews: Energy and Environment 3 (1), 42-59.

Sánchez, A. J., Gallego, A. J., Escaño, J. M., Camacho, E. F., 2018. Event-based MPC for defocusing and power production of a parabolic trough plant under power limitation. Solar Energy 174, $570-581$.

Sánchez, A. J., Gallego, A. J., Escaño, J. M., Camacho, E. F., 2019a. Adaptive incremental state space MPC for collector defocusing of 
1061 a parabolic trough plant. Solar Energy 184, 105-114.

1062 Sánchez, A. J., Gallego, A. J., Escaño, J. M., Camacho, E. F., 2019b.

1063 Thermal balance of large scale parabolic trough plants: A case 1064 study. Solar Energy 190, $69-81$.

1065 Sánchez, A. J., Gallego, A. J., Escaño, J. M., Camacho, E. F., 2020

Parabolic trough collector defocusing analysis: Two control stages vs four control stages. Solar Energy 209, $30-41$.

068 Schenk, H., Dersch, J., Hirsch, T., Polklas, T., 2015. Transient Simu-

1069 lation of the Power Block in a Parabolic Trough Power Plant. In:

1070 The 11th International Modelica Conference Versailles, France.

1071 Linköping University Electronic Press, Linköpings universitet, pp. $1072 \quad 605-614$

1073 SCHOTT Solar CSP GmbH, 2020. Schott ptr@70 receivers. (Ac1074 cessed: 04 August 2020).

1075 URL https://www.us.schott.com/csp/english/ 1076 schott-solar-ptr-70-receivers.html

1077 System Advisor Model (SAM). NREL, 2018. (Accessed: 04 August 1078 2020).

1079 URL https://sam.nrel.gov/

1080 Therminol VP1 HTF, 2020. (Accessed: 04 August 2020).

1081 URL https://www.therminol.com/products/Therminol-VP1

1082 Zarrella, A., Emmi, G., Vivian, J., Croci, L., Besagni, G., 2019. The

1083 validation of a novel lumped parameter model for photovoltaic

1084 thermal hybrid solar collectors: a new trnsys type. Energy Con-

1085 version and Management 188, $414-428$. 